\title{
In silico Evaluation of Molecular Virus-Virus Interactions Taking Place Between Cotton leaf curl Kokhran virus- Burewala strain and Tomato leaf curl New Delhi virus
}

\author{
Nida Fatima Ali ${ }^{1}$, Rehan Zafar Paracha ${ }^{\text {Corresp., } 2}$, Muhammad Tahir ${ }^{\text {Corresp. } 1}$ \\ ${ }^{1}$ Department of Plant Biotechnology, Atta-ur-Rahman School of Applied Biosciences (ASAB), National University of Science and Technology, Islamabad, \\ Federal, Pakistan \\ 2 Research Center for Modeling and Simulation (RCMS), National University of Science and Technology, Islamabad, Federal, Pakistan \\ Corresponding Authors: Rehan Zafar Paracha, Muhammad Tahir \\ Email address: rehan@rcms.nust.edu.pk, muhammad.tahir@asab.nust.edu.pk
}

Background. Cotton leaf curl disease (CLCUD) is a disease of cotton caused by begomoviruses, leading to a drastic loss in the annual yield of the crop. Pakistan has suffered two epidemics of this disease leading to the loss of billions in annual exports. The speculation that a third epidemic of CLCuD may result as consequence of the frequent occurrence of Tomato leaf curl New Delhi virus (ToLCNDV) and Cotton leaf curl Kokhran Virus-Burewala Strain (CLCUKoV-Bu) in CLCUD infected samples, demand that the interactions taking between the two viruses be properly evaluated. This study is designed to assess virus-virus interactions at the molecular level and determine the type of co-infection taking place.

Methods. Based on the amino acid sequences of the gene products of both CLCUKoV-Bu and ToLCNDV, protein structures were generated using different software, i.e. MODELLER, I-TASSER, QUARKS, LOMETS and RAPTORX. A consensus model for each protein was selected after model quality assessment using ERRAT, QMEANDisCo, PROCHECK Z-Score and Ramachandran plot analysis. The active and passive residues in the protein structures were identified using CPORT server. Protein-Protein Docking was done using HADDOCK webserver, and 169 Protein-Protein Interaction (PPIs) were performed between the proteins of the two viruses. The docked complexes were submitted to the PRODIGY server to identify the interacting residues between the complexes. The strongest interactions were determined based on the HADDOCK Score, Desolvation energy, Van der Waals Energy, Restraint Violation Energy, Electrostatic Energy, Buried Surface Area and Restraint Violation Energy, Binding Affinity and Dissociation constant $\left(\mathrm{K}_{\mathrm{d}}\right) .50$ ns Molecular Dynamic simulations were performed on complexes that exhibited the strongest affinity in order to validate the stability of the complexes, and to remove any steric hindrances that may exist within the structures.

Results. Our results indicate significant interactions taking place between the proteins of the two viruses. Out of all the interactions, the strongest were observed between Replication Initiation protein (Rep) of CLCuKoV-Bu with the Movement protein (MP), Nuclear Shuttle Protein (NSP) of ToLCNDV (DNA$B$ ), while the weakest were seen between Replication Enhancer protein (REn) of CLCuKoV-Bu with the REn protein of ToLCNDV. The residues identified to be taking a part in interaction belonged to domains having a pivotal role in the viral life cycle and pathogenicity. It maybe deduced that the two viruses exhibit antagonistic behavior towards each other, and the type of infection may be categorised as a type of Super Infection Exclusion (SIE) or homologous interference. However, further experimentation, in the form of transient expression analysis, is need to confirm the nature of these interactions and increase our understanding of the direct interactions taking place between two viruses.

Peer) reviewing PDF | (2021:02:58520:2:1:NEW 28 Jul 2021) 
1 In silico Evaluation of Molecular Virus-Virus

2 Interactions Taking Place between Cotton leaf curl

3 Kokhran virus- Burewala strain and Tomato leaf curl

4 New Delhi virus

5

6 Nida Fatima Ali ${ }^{1}$, Rehan Zafar Paracha ${ }^{2}$ and Muhammad Tahir ${ }^{1}$

7

8

9

10

11

12

13

14

15

20

21

22

23

24

25

26

27

28

29

30

31

32

33

34

1 Department of Plant Biotechnology, Atta-ur-Rahman School of Applied Biosciences (ASAB), National University of Sciences and Technology (NUST), Islamabad, Pakistan 2 Research Center for Modeling and Simulation (RCMS), National University of Sciences and Technology (NUST), Islamabad, Pakistan

Corresponding Authors:

Rehan Paracha ${ }^{2}$

Sector H-12 Islamabad, 44000, Pakistan

Email address: rehan@rcms.nust.edu.pk

Muhammad Tahir 1

Sector H-12, Islamabad, 44000, Pakistan

Email address: muhammad.tahir@asab.nust.edu.pk

(1)


35

36

37

38

39

40

41

42

43

44

45

46

47

48

49

50

51

52

53

54

55

56

57

58

59

60

61

62

63

64

65

66

67

68

69

70

71

72

73

74

\section{Abstract}

Background. Cotton leaf curl disease (CLCuD) is a disease of cotton caused by begomoviruses, leading to a drastic loss in the annual yield of the crop. Pakistan has suffered two epidemics of this disease leading to the loss of billions in annual exports. There is speculation of a third epidemic of CLCuD due to the frequent occurrence of Tomato leaf curl New Delhi virus (ToLCNDV) and Cotton leaf curl Kokhran VirusBurewala Strain (CLCuKoV-Bu) in CLCuD infected samples. The study is designed to study the nature of this coinfection and determine the molecular interactions taking place between the two viruses

Methods. Based on the amino acid sequences of the gene products of both CLCuKoV$\mathrm{Bu}$ and ToLCNDV, protein structures were generated using different software, i.e. MODELLER, I-TASSER, QUARKS, LOMETS and RAPTORX. A consensus model for each protein was selected after model quality assessment using ERRAT, QMEANDisCo, PROCHECK Z-Score and Ramachandran plot analysis. The active and passive residues in the protein structures were identified using CPORT server. ProteinProtein Docking was done using HADDOCK webserver, and 169 Protein-Protein Interaction (PPIs) were performed between the proteins of the two viruses. The docked complexes were submitted to the PRODIGY server to identify the interacting residues between the complexes. The strongest interactions were determined based on the HADDOCK Score, Desolvation energy, Van der Waals Energy, Restraint Violation Energy, Electrostatic Energy, Buried Surface Area and Restraint Violation Energy, Binding Affinity and Dissociation constant $\left(\mathrm{K}_{\mathrm{d}}\right) .50 \mathrm{~ns}$ Molecular Dynamic simulations were performed on complexes that exhibited the strongest affinity in order to validate the stability of the complexes, and to remove any steric hindrances that may exist within the structures.

Results. Our results indicate significant interactions taking place between the proteins of the two viruses. Out of all the interactions, the strongest were observed between Replication Initiation protein (Rep) of CLCuKoV-Bu with the Movement protein (MP), Nuclear Shuttle Protein (NSP), with HADDOCK scores of $-279.8 \pm 11.4,-241.5 \pm 8.2$, and Binding Affinities $\Delta \mathrm{G}$ of -16.4 and -14.0 (kcal mol-1). Consequently, the weakest interaction was observed between Replication Enhancer protein (REn) of CLCuKoV-Bu with the REn protein of ToLCNDV. The residues identified to be taking a part in interaction belonged to domains having a pivotal role in the viral life cycle and pathogenicity. It maybe deduced that the two viruses exhibit antagonistic behavior towards each other, and the type of infection may be categorized as a type of Super Infection Exclusion (SIE) or homologous interference. However, these findings need to be further evaluated by carrying our transient expression analysis and Bimolecular Fluorescence Complementation (BiFC) assay to confirm the nature of the interactions and increase our understanding of the direct interactions taking place between two viruses. 
75

76

77

78

79

80

81

82

83

84

85

86

87

88

89

90

91

92

93

94

95

96

97

98

99

100

101

102

103

104

105

106

107

108

109

110

111

112

113

114

\section{Introduction}

Cotton leaf curl disease (CLCUD) is a viral disease and notable menace to cotton productivity. CLCUD has been a serious threat to cotton production in Pakistan and India, leading to severe economic losses. (Mansoor et al., 2003; Zubair et al., 2017). Vein thickening, leaf curling, and formation of small leaf-like enations on the lower surface of the leaf are the characterizing features of this disease (Padidam, Beachy, \& Fauquet, 1995). The viral agents associated with this disease are known as CLCuD associated begomoviruses (CABs), which belong to the family Geminiviridae, and genus Begomovirus (Mansoor et al., 1999). These viruses are transmitted by the vector whitefly (Bemisia tabaci) (Briddon \& Markham, 2000). Geminiviruses are

phytopathogenic viruses having a wide variety of hosts. They consist of circular, single-stranded DNA (ssDNA) genomes that are packed into icosahedral twinned particles, a feature unique to this family. Based on their host range, the vector of transmission, and genome arrangement these viruses have been arranged into nine genera (Varsani et al., 2017). Among them, the genus begomovirus is the most prevalent and diverse (Fauquet et al., 2008). The genome of begomoviruses can be monopartite, consisting of one DNA-A component or bipartite, comprising of two components, DNA-A and DNA-B, each having a size of 2.5 to $3.0 \mathrm{~kb}$ (Accotto et al.,1993). The genome of monopartite begomoviruses is small and consists of 6 to 8 Open reading frames (ORFS). The DNA-A encodes for the Coat protein (CP) and V2/AV2 protein in the virion sense strand, while the Replication initiation protein (Rep), Transcription Activation Protein (TrAP), Replication Enhancer Protein (REn), and the C4/AC4 proteins are encoded by a complementary sense strand. (R. Hull, 2014). Some begomoviruses are occassionally associated with a symptom modifying DNA betasatellite (Family Tolecusatellitidae, Genus Betasatellite). These satellites are typically 1350 bp in size, incorporating an adenine-rich region, the satellite conserved region (SCR) of a predicted hairpin structure that contains a loop region along with a single ORF that is named $\beta C 1$, coded by the complementary strand (Briddon \& Stanley, 2006). In the case of bipartite begomovirus, in addition to DNA-A, a DNA-B component is also present that encodes for Movement protein (MP) and Nuclear Shuttle Protein (NSP). Viral proteins perform various functions inside the host cell. Rep is a multifunctional protein that carries out rolling circle replication (RCR) as it is involved in ATPase activity (Desbiez et al.,1995), it performs gene modulation and interacts with viral and host factors including REn, the Proliferating Cell Nuclear Antigen (PCNA), and Retinoblastoma-related Protein (pRBR) (Pradhan, Vu, \& Mukherjee, 2017). It is the most conserved geminiviral protein that has a critical role in the assembly of the viral replisome, a complex comprising of host and viral protein factors forming a DNA replication fork on the viral DNA (Ruhel \& Chakraborty, 2019). TrAP creates a favorable cellular environment for viral replication, it plays a key role in viral pathogenicity, induces the transactivation of the host as well as viral genes (Haley et al., 1992), and causes 
115 suppression of gene silencing (Babu et al.,2018). REn is required for the optimal 116 replication of the viruses, interacts with Rep, and enhances the ATPase activity of this 117 protein (Pasumarthy et al., 2010). REn undergoes homo-oligomerization as it interacts 118 with PCNA and pRBR, two host proteins that have a major role in host-cell cycle (Settlage et al., 2005a). C4 protein consists of a highly conserved N-terminal myristoylation motif that is an irreversible post-translational modification in the protein structure, this domain functions as a RNA silencer in the cell (Fondong, 2013). CP encapsulates the ssDNA of the virus, protecting the nucleic acid and aiding its transmission both within and between plants (Frischmuth \& Stanley, 1998). V2 protein suppresses RNA silencing and plays a role in viral infectivity and spread (Rojas et al., 2001). MP carries out cell-to-cell and long-distance movement of the virus while NSP transports the viral genomes from the nucleus to the cytoplasm and then back to the nucleus, within the cell. MP guides the NSP-DNA complexes, as it modifies the plasmodesmata in the host cell and carries out trafficking of this complex from cell to cell. $\beta C 1$ is involved in post-transcriptional gene silencing, it is a suppressor of transcriptional gene silencing and interferes with the metabolic and signaling pathways of the host cell (Brown et al., 2015). Details of begomoviral genome and the domain organization of different proteins are provided in Fig. 1. The Indo-Pak subcontinent has observed two CLCuD epidemics in the recent past. The first being the "Multan Epidemic", occurring from 1989-1999 (Sattar et al., 2013) that led to a country wide spread of the disease, resulting in $80 \%$ yield loss causing a shortfall of US $\$ 5$ billion to Pakistan's economy (Briddon \& Markham, 2000). In 2001, a recombinant begomovirus, the Cotton leaf curl Kokhran virus-Burewala strain (CLCuKoV-Bu) was observed near the town of Burewala in Punjab, Pakistan (Shahid et al., 2003). The unique feature of this new recombinant virus was that it possessed a truncated TrAP protein, consisting of only 35 amino acids (Amrao et al.,2010). Since the breakdown of resistance against CLCuD in 2001/2002 only the CLCuKoV-Bu, a monopartite begomovirus, in association with a recombinant form of Cotton leaf curl Multan beta-satellite (CLCUMuB) (Haider et al., 2006) has been associated with the disease. This spread of infection gave way to the second epidemic, which was observed from 2002 to 2013-2014. This was referred to as the "Burewala Epidemic" (Sattar et al., 2013). Until the Burewala endemic, only monopartite begomoviruses, in association with DNA satellites had been associated with the disease but the existence of bipartite begomovirus, the Tomato leaf curl New Delhi virus (ToLCNDV) in the CLCuD affected samples of the Cotton plant. (Zaidi et al., 2016) has raised concerns. This has led to the conjecture that a third epidemic maybe possible owing to the dual infection of these two begomoviruses, in the disease-affected host plants (Sattar et al., 2017). During dual or mixed infection of viruses, the interaction may range from synergism to neutralism to antagonism (Moreno \& López-Moya, 2020). Virus-virus interactions (VVIs), defined as the measurable differences taking place in the plant during infection of one virus, 
155

156

157

158

159

160

161

162

163

164

165

166

167

168

169

170

171

172

173

174

175

176

177

178

179

180

181

182

183

184

185

186

187

188

189

190

191

192

193

194

accompanied by the concurrent or prior infection by a different viral strain or viral species. VVIs may be categorized as direct or indirect, based on the nature in which they occur. Direct VVIs take place between viral gene products of co-infecting viruses, while the indirect VVIs are observed due to changes in the host environment, these are also termed indirect environment interactions (DaPalma et al., 2010). The interaction taking place between the two begomoviruses under study are yet to be determined. This study is designed to understand the direct interactions taking place between the proteins of CLCuKoV-Bu and ToLCNDV. To our knowledge, this is the first time such a study has been designed. VVls were observed in the form of electrostatic interactions, detected after performing molecular docking and undertaking the binding affinities and dissociation energies of the docked structures. By mapping out the interacting residues, the domains taking part in the interaction were highlighted. Based on our results, it is hypothesized that although concerns exist that dual infection could lead to a further epidemic of CLCuD, the opposite may also be true.

\section{Materials \& Methods}

\section{Sequence Retrieval and PSI-BLAST Analysis}

Gene sequences for CLCuKoV-Bu and ToLCNDV were retrieved from Uniprot (www.uniprot.org). For CLCuKoV-Bu, the sequences of Rep (AOAOS2MSV0), TrAP(A0A0S2MST9), Ren (AOA0S2MSU6), C4 (A0A2K8HNC7), CP (A0A0S2MSU9), and $\mathrm{V} 2$ (AOA0S2MSV4) were retrieved. Along with the sequence for $B C 1$ (A0A0K2SU38) protein from the associating beta-satellite, CLCuMuB. For ToLCNDV, the sequences for Rep (A0A565D4R1), TrAP (A7WPF3), Ren (A6PYE1), AC4 (A7U6D0), CP (A0A2Z2GPB3), and AV2 (A0A3G2KQ59) proteins from DNA-A, and MP (E6N191) and NSP (A0A2P2CKV4) from DNA-B were obtained. These sequences were submitted to NCBI provided PSI-BLAST (https://www.ncbi.nlm.nih.gov/BLAST/) to identify homologous protein structures present in Protein Data Bank (PDB) (www.rcsb.org/pdb).

\section{Protein Structure Prediction}

Three different approaches were used for predicting the structure of the proteins of the two viruses. If the sequence identity for the viral gene products was greater than $75 \%$ then a homology-based approach was adopted, if it was less than $75 \%$ then threadingbased and ab initio approaches were used for protein structure prediction. Homology modeling based structure prediction was performed using MODELLER 9.24 (Webb \& Sali, 2014) where the homologous proteins were retrieved from PDB and were used as a template for modeling. Threading based approach was employed by submitting the amino acid sequences of the proteins, in FASTA format to I-TASSER (Iterative Threading ASSEmbly Refinement) webserver (J. Yang \& Zhang, 2015) (http://zhanglab.ccmb.med.umich.edu/l-TASSER/), LOMETS version 3 webserver (LOcal MEta-Threading Server) (S. Wu \& Zhang, 2007) (https://zhanglab.ccmb.med.umich.edu/LOMETS/), and RaptorX webserver (Källberg et 
195

196

197

198

199

200

201

202

203

204

205

206

207

208

209

210

211

212

213

214

215

216

217

218

219

220

221

222

223

224

225

226

227

228

229

230

231

232

233

234

al., 2012) (http://raptorx.uchicago.edu). I-TASSER is one of the most widely used online servers that is used for protein structure prediction and annotation of the structurebased functions. The server generates $3 \mathrm{D}$ models by matching the biological insights of the target proteins with the structures of known proteins present in biological databases (Roy, Kucukural, \& Zhang, 2010). LOMETS software is valuable in predicting the tertiary structure of the proteins. In this software, a 3D model is generated based on a consensus, devised by taking into consideration a number of models predicted by nine individual threading servers (S. Wu \& Zhang, 2007). RaptorX program is useful in predicting protein models when no close template exists. (Peng \& Xu, 2009; Peng \& Xu, 2010) $A b$ initio approach was performed by submitting gene sequences comprising of 200 or fewer amino acids to the QUARK webserver (Xu \& Zhang, 2013) (https://zhanglab.ccmb.med.umich.edu/QUARK/).

\section{Model Quality Assessment}

The quality of the predicted protein models was evaluated using different methods. Stereochemical quality and structural rationality were evaluated using the ERRAT (Colovos \& Yeates, 1993) (https://servicesn.mbi.ucla. edu/ERRAT/), global model quality assessment was done through QMEANDisCo (Qualitative Model Energy Analysis Distance Constraint) (Benkert, Künzli, \& Schwede, 2009) (https://swissmodel.expasy.org/qmean/. QMEANDisCo is a composite program that provides global and local quality estimates for the protein model. The distant constraint (DisCo) feature evaluates the pairwise distance that exists within the residues in the model and assesses the multitude of constraints that may exist within the structure, based on the information from experimentally determined protein structures that are homologous to the protein model being assessed. It is calculated as the average score per residue and occurs in the range of 0 to 1 (Studer et al., 2020). ProSA-Web Z-Score (Wiederstein \& Sippl, 2007) (https://prosa.services.came.sbg.ac.at/prosa.php) is a diagnostic tool that is based on the statistical analysis of all the available protein structures. This program relates to the overall quality score of the protein structure in the form of a plot comprising experimentally determined protein structures that are present in the PDB. The overall quality of the protein models was estimated using global checks on the model's stereochemistry, geometry, and other structural properties. This was done utilizing Ramachandran Plot, obtained through PROCHECK (Laskowski et al., 1993)

\section{Intra-viral and Inter-viral Protein-Protein interactions (PPI)}

Intra-viral PPI, (taking place between the proteins of the same viruses) and Inter-viral PPI (taking place between the proteins of two different viruses) were performed to evaluate whether a stronger interaction is observed within the proteins of the same virus, or between the proteins of different viruses. PPIs of the proteins of CLCuKoV-Bu and ToLCNDV encoded proteins were studied using the High Ambiguity Driven biomolecular DOCKing (HADDOCK2.2) web portal (De Vries, Van Dijk, \& Bonvin, 2010; 
235 Van Zundert et al., 2016) (http://haddock.science.uu.nl). HADDOCK is a widely used

236 docking tool that is based on information-driven docking protocol. It requires the

237 generation of an Ambiguous Interaction Restraints (AIRs) file for a manual run. The

238 prerequisite to the AIRs file is to define the active and passive residues present at the

239 interface of each molecule. These residues are defined using experimental data or

240 through bioinformatic predictors like CPORT (Consensus Prediction Of Residues in

241 Transient complexes) (de Vries \& Bonvin, 2011)

242 (http://haddock.science.uu.nl/services/CPORT/). HADDOCK server distinguishes

243 between two types of residues. The active residues must be present at the interface

244 between the two molecules and maybe in contact with the active or passive residues of

245 the other molecule, if not, an energy penalty would be paid. The passive residues, on

246 the contrary, may be present at the interface but are not penalized if found otherwise

247 (Hinchliffe \& Harwood, 2019). A HADDOCK run is set up by providing two proteins

248 whose interaction is to be evaluated, in PDB format to the server. The list of active and

249 passive residues is also provided as input data for each protein. The docking protocol

250 follows three steps, rigid body minimization, semi-flexible refinement, and the final

251 refinement of the models that take place in an explicit solvent. 1,000 models are

252 produced by default, as a result of the initial rigid-body docking. The default number of

253 models is reduced to 200 after semi-flexible refinement and final refinement in water.

254 These final water-refined models are clustered and ranked based on their respective

255 HADDOCK score. This clustering is done based on pairwise Root Mean Square

256 Deviations (RMSD), with the default value of RMSD being set to a cutoff of $7.5 \AA$, and

257 the minimum number of structures to define a cluster is four (by default) (Saponaro et

258 al., 2020). Detailed statistics that represent the average values of the HADDOCK score

259 along with other standard energies including Van der Waals, Desolvation energy,

260 Restraint violation energy, Intermolecular binding energy, non-bonded interaction

261 energy, buried surface area, and Z-score were calculated for the high scoring

262 complexes in each cluster.

263 Determination of Interacting Residues

264 The protein-protein complexes were selected based on their HADDOCK scores and

265 associative energies. The binding energies and the intermolecular contacts present

266 within the complexes were determined by submitting the top scoring complex, for each

267 interaction, to PRODIGY (PROtein binDIng enerGY predict) webserver (Vangone \&

268 Bonvin, 2015) http://milou.science.uu.nl/services/PRODIGY. It is a contact-based

269 predictor of binding affinity, which is described in the form of Gibbs free energy $(\Delta G$,

270 kcal mol-1) and dissociation constant ( $\left.\mathrm{K}_{\mathrm{d}}, \mathrm{M}\right)$. Interatomic contacts (ICs) at a distance

271 threshold of about $5.5 \AA$ within the protein-protein complex are counted and classified

272 based on the Polar/Non-Polar/Charged nature of the interacting amino acids. The

273 server also provides the number of residues in the Non-Interacting Surface (NIS) of the

274 protein (Vangone \& Bonvin, 2017). Both ICs data, along with the information of NIS 
275 properties influence the binding affinities of the complexes (Kastritis et al., 2011). The 276 structures were visualized through PyMol (Schrödinger, 2015.) (https://pymol.org/). By 277 performing sequence analysis through Jalview software (Waterhouse et al., 2009)

278 (https://www.jalview.org/) the interacting residues determined through PRODIGY server were highlighted, and the domains these residues belonged to, were identified.

282 Molecular Dynamics (MD) Simulations of Docked Protein Complexes Molecular Dynamics (MD) simulations provide identification of the conformational

283

284

285

286

287

288

289

290

291

292

293

294

295

296

297

298

299

300

301

302

303

304

305

306

307

308

309

310

311

312

313

changes and the evaluation of the molecular interactions that are present within the complex assembly (Wang, Wu, Lee, \& Yu, 2020). MD simulations were performed for the viral complexes; Complex 1: Rep (CLCuKoV-Bu) - MP (ToLCNDV); Complex 2: Rep (CLCuKoV-Bu) - NSP (ToLCNDV) that exhibited the greatest affinity, lowest binding energies, and high dissociation energies among all the interactions. MD simulations were performed by using Groningen Machine for Chemical Simulations (GROMACS) v.5.1 (Abraham et al., 2015) . It is a reliable tool that is used to evaluate different biological models within realistic cellular environments. Default parameters were used for the simulations. All the systems were solvated in a cubic water box, with the complexes being placed at least $1.0 \mathrm{~nm}$ from the edge of the box. The Optimized Potential for Liquid Simulation (OPLS) force field (Robertson, Tirado-Rives, \& Jorgensen, 2015) was used. The physiological $\mathrm{pH}$ of the systems was maintained using the Single Point Charge Extended (SPCE) water model (Y. Wu, Tepper, \& Voth, 2006), and to neutralize the systems, $\mathrm{Na}^{+}$or $\mathrm{Cl}^{-}$ions were added. The steepest descent approach was used for energy minimization for 50,000 cycles. The systems were then equilibrated for a constant number of particles, volume, temperate (NVT), and a constant number of particles pressure, temperature (NPT). Following the equilibrations, 50 ns simulation was performed for the protein complexes.

\section{Results}

\section{Primary data Retrieval}

Sequences for the genes of CLCUKoV-Bu and ToLCNDV were retrieved from Uniprot, and PSI-BLAST analysis were performed to find homologous protein sequences. The information is provided in Table 1.

\section{Protein Structure Prediction and Assessment}

3D structures of the proteins were generated through homology, threading and ab initiobased approaches, by using five different software. Homology modeling was performed using MODELLER. Through this approach, the structures of Rep and CP of CLCuKoV$\mathrm{Bu}$ and ToLCNDV, which showed percentage sequence identity greater than $75 \%$ after PSI-BLAST analysis, were produced. In the case of ab initio modeling, done through QUARK, only the proteins comprising of less than 200 amino acids were modeled. These included the structures of TrAP, REn, C4, V2 proteins of CLCuKoV-Bu, $\beta C 1$ protein of CLCUMuB, and TrAP, REn, C4, and V2 proteins of ToLCNDV. By using 
314 software like I-TASSER, LOMETS, and RAPTORX, structures for all the proteins of the

315 two viruses were produced, by the threading-based approach.

316 Protein Structure Quality Assessment:

317 The protein structures generated through different approaches were evaluated using

318 ERRAT, QMEAN, ProSA Z-Scores, and Ramachandran plot, and a consensus structure

319 for each protein was selected based on the results of these assessment tools. The

320 structures produced by Homology modeling were the least stable, while those

321 generated by $A b$ initio and threading based approaches proved to be the most stable.

322 QUARK and I-TASSER were the most efficient programs. The overall quality of the structures assessed by ERRAT was found to be greater than $80 \%$ for the models of all proteins of both the viruses, except for $\beta C 1$ of $C L C u M u B$, which had a value of $74 \%$. The QMEANDisCo score, of all the protein structures, exhibited structure stability with their scores occurring within the given range. The Ramachandran plot exhibited that the maximum number of residues in the favorable and allowed regions. The Z-score by ProSA-web exhibited the structures were reliable, with the energy conformation of the models lying within a range of scores that are usually found for similar-sized proteins. Detailed results of structure evaluation are presented in Table S1. The structure for the consensus model of each protein is provided in Fig. 2.

PPIs were performed to access the intermolecular interactions that may be taking place between the proteins of the two viruses. This is a crucial step in accessing the domains taking part in the interaction and identifying the proteins showing the most affinity for the proteins of the other virus. CPORT analysis was performed to identify the active and passive residues of the proteins, provided in Table S2.

The PPIs performed using HADDOCK2.2 webserver showed affinity among the proteins of the two viruses. In total 169 interactions were performed, with 56 interactions taking place between the proteins of CLCuKoV-Bu and ToLCNDV, 49 between the proteins of CLCuKoV-Bu and CLCuKoV-Bu, and 64 between the proteins of ToLCNDV and ToLCNDV. The inter-viral PPIs, between CLCuKoV-Bu and ToLCNDV were the strongest based on the HADDOCK scores and corresponding energy values. Rep and CP of CLCuKoV-Bu and MP and NSP of ToLCNDV were most actively involved in the interactions. Among all the interactions, the strongest that were observed involved the Rep (CLCuKoV-Bu) protein. As was seen in the interaction of Rep (CLCuKoV-Bu) - MP (ToLCNDV), Rep (CLCuKoV-Bu) - NSP (ToLCNDV) and Rep (CLCuKoV-Bu) - Rep (ToLCNDV). Another significantly strong interaction was observed between REn (CLCuKoV-Bu) - NSP (ToLCNDV). The docked structures were evaluated based on their RMSD values and energies like, desolvation energy, Van der Waals energy, electrostatic energy, restraint violation energy, buried surface area and the Z- score, that is based on the probability of the results among the various clusters. The details of these interactions, HADDOCK scores and energy values of the complexes are provided 
354 in Fig. 3. Detailed results of intra and inter viral PPIs are presented in Table S3 while

355

356

357

358

359

360

361

362

363

364

365

366

367

368

369

370

371

372

373

374

375

376

377

378

379

380

381

382

383

384

385

386

387

388

389

390

391

392

some of the stronger interactions based on the HADDOCK scores and corresponding energy values are presented in Table 2 .

Overall, all the observed interactions exhibited strong binding affinity, based on the recorded energy values, only some interactions with the REn protein of CLCuKoV-Bu seemed to be weak, exhibiting low dissociation energy and low affinity values. Details of the energy values for the observed interactions are provided in Table S4 and binding affinity and dissociation constant $\left(\mathrm{K}_{\mathrm{d}}\right)$ values of the docked structures, calculated by the PRODIGY webserver are provided in Table S5.

\section{Residue Identification}

The amino acids residues taking part in the interaction were determined by submitting the docked complexes to PRODIGY server. The maximum number of interacting residues among all the strong PPIs belonged to Polar-Apolar ICs, while the minimum number belonged to Charged-Charged ICs. Details of charges of the interacting residues are given in Table S6.

Based on the knowledge of these interacting residues, the domains involved in the interaction were identified using Jalview software. For the two begomoviruses, similar domains were identified to take part in the interactions. This was deduced after taking into account all 169 interactions and identifying the interacting amino acid residues. For the Rep (CLCuKoV-Bu) and Rep (ToLCNDV), the DNA Binding and the Helicase/ATPase domains were involved in interactions. The majority of the interacting residues belong to the helicase domain, while only one amino acid residue from the DNA binding domain seemed to be involved, these residues are presented in Fig. $4 \mathrm{~A}$. TrAP (CLCuKoV-Bu) was truncated and only the amino acids from the nuclear localization sequence (NLS) were involved in interactions, while in case of TrAP (ToLCNDV) the Zinc finger-like motif, the programmed cell death (PCD) domain and the acidic region at the $C$ terminal were involved in the interactions: Fig. 4 B.

The REn protein of CLCuKoV-Bu and ToLCNDV, exhibited that both $\mathrm{N}$ and $\mathrm{C}$ terminals were involved in interactions. The interacting residues occurred in the Rep binding domain, PCNA binding domain, SINAC1 binding domain, and the retinoblastoma related protein binding regions: Fig. 4 C. AC4 (ToLCNDV) was smaller in size as compared to $\mathrm{C} 4$ (CLCuKoV-Bu), however, in both the proteins, residues from the $\mathrm{N}$-terminal myristoylation sequence, the S-adenyl methionine synthetase interacting residue and the SHAGGY-like Kinase interacting domain were involved in the interaction, Fig. $5 \mathrm{~A}$. The CP of both the begomoviruses had majority of the interacting amino acids belonging to the Nuclear Localization Signal (NLS) region, and the DNA binding domain present at the $\mathrm{N}$-terminal. The other domains of this protein involved in interaction included the Cell Wall targeting motif (CW), the Nuclear Export Signal (NES) and the NLS domain present at the $\mathrm{C}$ terminal, Fig. $5 \mathrm{~B}$.

Peer) reviewing PDF | (2021:02:58520:2:1:NEW 28 Jul 2021) 
393

394

395

396

397

398

399

400

401

402

403

404

405

406

407

408

409

410

411

412

413

414

415

416

417

418

419

420

421

422

423

424

425

426

427

428

429

430

431

432

V2 (CLCuKoV-Bu) showed participation of the Putative Protein Kinase C (PKC) domain and the WCCH domain in interaction, while for the AV2 (ToLCNDV), interacting residues were only present in the latter domain, and no participation was shown for the former, Fig. 5 C.

The $\beta C 1$ protein of the CLCUMUB had several residues involved in the interactions, ranging from the center to the $\mathrm{C}$-terminal of this protein. Interacting residues also occurred in the myristoylation domain of this protein, Fig. $6 \mathrm{~A}$.

MP (ToLCNDV-DNA B) had the strongest interaction with the proteins of CLCuKoV-Bu and it exhibited interacting residues from the Pilot, anchor and oligomerization domains. with the majority of the interacting residues belonging to the latter. As the NSP interacting domain also overlaps with the anchor and oligomerization domains, it may also be involved in the interactions, Fig. 6 B.

The NSP (ToLCNDV- DNA B) had the interacting residues present in the NLS-A region while the residues from NLS-B did not take part in interactions. The residues from the initial parts of the DNA binding domain, the MP interacting domain and the AtNSI interacting domains were involved in the interactions, Fig. 6 C.

\section{Molecular Dynamics Simulations}

To understand key structural details, in terms of stability, structural integrity, and compactness of the complexes of the interacting proteins, MD simulations were carried out. The HADDOCK server also conducts water-based simulations, therefore, to remove steric hindrances present within the structures of the complexes $50 \mathrm{~ns}$ simulations were performed. The Root Mean Square Deviation (RMSD) and Root Mean Square Fluctuation (RMSF) analyses provide information about structural stability and flexibility of the protein-protein complexes.

RMSD value for the average MD simulation conformation is used to quantitate how much the protein has changed or how much the conformations vary in the duration of the simulation. The results show that the maximum, minimum and average RMSD values for complex 1 are $0.65,0.25,0.45$ and for complex 2 are 0.78, 0.2, 0.65, exhibiting structure stability of the molecules throughout the duration of the simulation.

Fluctuation of the individual amino acid residues within the complexes can be calculated based on the RMSF value, obtained from the 50 ns MD simulation. The results show that the maximum, minimum and average RMSF values are 1.45, 0.06 and 0.75 for complex 1 and $1.25,0.1$ and 0.675 for complex 2 . Low average RMSF values indicate that individual amino acids exhibit stability in the dynamic state of the protein during MD simulation. The Radius of gyration $\left(R_{g}\right)$ was calculated to determine the compactness of the complexes. $R_{g}$ provides the overall dimensions of the protein structure as it shows the mass-weighted root mean square distance of a collection of atoms from their common center of mass. Results show the average $R_{g}$ value of 2.66 for complex 1 and 2.825 for complex 2 for a $50 \mathrm{~ns}$ simulation at $300 \mathrm{~K}$. Hydrogen bonds are considered to play a vital role in the structural stability and molecular interaction of the proteins. The 
433 greater number of hydrogen bonds helps to maintain the stability of the structures. The

434 hydrogen bond analysis was carried out through the VMD 1.9.4 program (Humphrey,

435 Dalke, \& Schulten, 1996) for the MD trajectories.

436 The results obtained through these analyses signified that the interactions between the

437 protein structures were stable and the docked complexes remained structurally sound

438 throughout the duration of the simulation. Graphical representation of the results for 439 complexes 1 and 2 are provided in Fig. 7.

440 Discussion

441 The coinfection of ToLCNDV and CLCuKoV-Bu have raised the speculation of a third 442 epidemic of CLCuD (Sattar et al., 2017). Direct interactions taking between the proteins 443 of CLCuKoV-Bu with the proteins of ToLCNDV have been observed, in order to hypothesise the nature of the interactions taking place between two begomoviruses. Mixed infections of ToLCNDV with several monopartite begomoviruses have been reported, and the virus is known to infect a wide range of plants belonging to various plant families, including Cucurbitaceae, Solanaceae, Malvaceae, Euphorbiaceae and Fabaceae (Zaidi et al., 2017). In case of such infections, each viral population changes the environment and fitness landscape inside the host, and the success of any virus depends not only on its adaption to the host but also on how it interacts with the other virus (Elena, Bernet, \& Carrasco, 2014). In this study, in silico models were generated to test the hypothesis that the coinfecting viruses interact with each other. Such models may help in understanding the pathogenesis and pathophysiology of a disease, which can lead to the development of control strategies (Barh et al., 2013). The involvement of host factors is omitted for simplicity purposes along with presuming the differences that may occur in localization and the timing of events. A limitation of this study is that the structure prediction of the viral proteins had to be primarily based on template-free methods, due to the lack of homologous protein structures available in the PDB (Chen \& Weng, 2003; van Zundert et al., 2016). Another limitation is the inability of the protein models to account for the high rates of mutation occurring in the viral protein sequences (Echave, Spielman, \& Wilke, 2016). Our results indicate a strong affinity between the proteins of the two begomoviruses, which may influence their rate of infection and spread within the host. From among the proteins of CLCuKoV-Bu and CLCuMuB, the strongest interactions that were observed involved the Rep protein, similarly for ToLCNDV the proteins of DNA-B were involved in the strongest interactions. Rep of CLCuKoV-Bu exhibited a strong affinity for the proteins of the other virus with the ATPase/Helicase domain of Rep protein most frequently involved in the interactions. Rep is the most important protein in the viral life cycle. It is involved in a number of processes, ranging from the transcriptional activation and suppression of viral gene products, interacting with various factors in the host cell and ATPase/Helicase activity. The involvement of the ATPase domain of Rep in PPIs may hinder the RCR mechanism of viral replication that can reduce the number of viral agents in the host cell (Desbiez et 
473 al., 1995). Interaction of Rep with REn promotes accumulation of viral DNA (Settlage et

474 al., 2005b), and further interaction with CP suppresses the nicking and ligation activity

475 of this protein (Malik et al., 2005). The strong binding of Rep with MP and NSP may

476 cause hindrance in the formation of these complexes. The $\mathrm{N}$ and $\mathrm{C}$ terminal domains of

477 Rep reported to be involved in PPIs are important for DNA recognition, binding and

478 ATPase/Helicase activity (Chatterji, et al.,2000). The REn protein exhibited a very 479 strong interaction with the NSP of ToLCNDV (DNA-B). Although REn is capable of 480 homo-oligomerization (Settlage et al., 2005a) it exhibited very weak bonding with the 481 REn of the different virus and a stronger interaction was observed between REn 482 proteins of the same virus.

483 The TrAP of CLCuKoV-Bu comprising a coding capacity of 35 amino acids is 484 considered truncated (Amrao et al., 2010). This protein suppresses post-transcriptional 485 gene silencing (PTGS) in the host and modulates microRNA (miRNA) expression. 486 These characters are retained in the complete $(\sim 134$ aa) as well as in the truncated 487 ( 35 aa) TrAP proteins (Akbar et al., 2016). This protein is capable of undergoing self488 interaction with the TrAP-TrAP complexes accumulating in the nucleus (X. Yang et al., 489 2007; Guerrero et al., 2020). The interactions observed between the TrAP (CLCuKoV$490 \mathrm{Bu}$ ) - TrAP (ToLCNDV) and TrAP (ToLCNDV) - TrAP (ToLCNDV), validate the self491 interaction concept. A strong interaction of CP (CLCuKoV-Bu) was observed with TrAP 492 (ToLCNDV). This is in validation with the work of Guerrero et al., 2020, which states that 493 TrAP protein is involved in regulating the expression of CP protein during the viral 494 lifecycle. C4 protein suppresses the post-transcriptional gene silencing (PTGS) by 495 interacting with the NbSAMS2 host protein. The first 20 amino acid residues of the 496 protein play a crucial role in the binding of this protein (Ismayil et al., 2018). The results 497 of the current study show the first 23 amino acids residues, comprising the $\mathrm{N}$-terminal 498 myristoylation and S-adenosyl methionine synthetase regions (Fondong, 2019) to be 499 involved in the PPIs.

500 The MP and NSP of DNA-B of ToLCNDV are involved in the cell to cell transport of the 501 viral products and in the export of the Viral DNA from the nucleus (Zhang, Wege, \& 502 Jeske, 2001), these functions are achieved by the interaction between MP and the NSP 503 (Rojas et al.,1998). Our findings show these two proteins are actively involved in inter504 viral interactions. As was observed in the interactions between the proteins of DNA-B of 505 ToLCNDV with the $\beta C 1$ (CLCuMuB), suggesting an association between the 506 betasatellite and the bipartite begomovirus (Jyothsna et al., 2013). A significant 507 interaction noted between $\beta C 1$ (CLCuMuB) and MP (ToLCNDV), with a HADDOCK 508 score of -199 and $\Delta G$ value of $-15.8\left(\mathrm{kcal} \mathrm{mol}^{-1}\right)$, indicated that the protein-protein 509 complex was stable, with the amino acids from the Myristoylation-like motif domain of $510 \beta C 1$ and Pilot domain, Anchor Domain and Oligomerization Domain domains of MP 511 were involved in the interaction. 
512 The outcome of interactions between dual viral infections may range from synergism to 513 neutralism to antagonism, with each having a direct impact on the health of the plant. In 514 case of no change in the viral accumulation as compared to single virus infection, the 515 state is referred to as neutralism, whereas if the accumulation of either one or both of 516 the viral agent is enhanced it is called synergism and if the population of either one or 517 both viral agents is reduced it is termed as antagonism (Moreno \& López-Moya, 2020).

518 The direct interactions between the gene products of the two similar begomoviruses 519 show that key domains, playing monumental roles in the viral life cycle, from replication 520 of the virus to its export from the nucleus to the spread to the other cells take part in the 521 PPIs. These interactions are hypothesized to limit the growth of both CLCuKoV-Bu and ToLCNDV, limiting their spread and in effect reduce the virulence of the CLCuD. Therefore, this may be classified as an antagonistic interaction. This mechanism may be a type of cross-protection or homologous interference, that is an antagonistic interaction occurring between similar viruses (Syller \& Grupa, 2016) Antagonistic interactions are relatively less reported as compared to synergistic interactions, because they result in disease attenuation in contrast to exacerbation and therefore may go unnoticed (Díaz-Muñoz, 2019). These findings are based on in-silico research

529 and serve as the first step towards understanding the mechanism in which virus-virus interactions could be taking place. It is important to carryout in planta experimentation

531 and evaluate these findings.

\section{Conclusions}

533 The present study aims to develop an understanding of the nature of coinfection taking place between the proteins of CLCuKoV-Bu and ToLCNDV on the basis of the speculations that this coinfection can lead to a third epidemic of the CLCuD. VVIs were determined by taking into account the PPI between the proteins of the two viruses. The findings reveal domains of viral proteins, responsible for performing crucial roles in the replication and translocation in the viral life cycle interacting with each other. This interaction shows that the proteins of the two co-infecting viruses may have an affinity, and bind easily to one another, altering the course of the disease in the host. The effect such interactions may have on the host can only be confirmed by in vivo analysis of

542 protein complexes within the host plant The residues and domains highlighted in this

543 study may provide a valuable insight into virus-virus interactions and can serve a lead in

544 understanding the elusive VVIs. Strong interactions among the key domains of the

545 proteins of the two co-infecting viruses suggest the interaction maybe antagonistic or a 546 type of cross-protection or homologous interference, however such claims can only be 547 proved by carrying out further experimentation.

\section{Acknowledgements}

549 The present study was completed in 2020, as a joint collaboration between Atta ur 550 Rahman School of Applied Biosciences (ASAB) and Research Centre for Modelling and 
551

552

553

554

555

556

557

558

559

560

561

562

563

564

565

566

567

568

569

570

571

572

573

574

575

576

577

578

579

580

581

582

583

584

585

586

587

588

589

590

591

592

593

594

595

596

Simulation (RCMS) at the National University of Sciences and Technology. This research would not have been possible without the support of these two host facilities.

\section{References}

Abraham, M. J., Murtola, T., Schulz, R., Páll, S., Smith, J. C., Hess, B., \& Lindahl, E. (2015). GROMACS: High performance molecular simulations through multi-level parallelism from laptops to supercomputers. SoftwareX, 1-2, 19-25.

https://doi.org/https://doi.org/10.1016/j.softx.2015.06.001

Accotto, G. P., Mullineaux, P. M., Brown, S. C., \& Marie, D. (1993). Digitaria streak geminivirus replicative forms are abundant in S-phase nuclei of infected cells. Virology, 195(1), 257-259. https://doi.org/10.1006/viro.1993.1369

Akbar, F., lqbal, Z., Briddon, R. W., Vazquez, F., \& Saeed, M. (2016). The 35-amino acid $\mathrm{C} 2$ protein of Cotton leaf curl Kokhran virus, Burewala, implicated in resistance breaking in cotton, retains some activities of the full-length protein. Virus Genes, 52(5), 688-697. https://doi.org/10.1007/s11262-016-1357-3

Amrao, L., Amin, I., Shahid, M. S., Briddon, R. W., \& Mansoor, S. (2010). Cotton leaf curl disease in resistant cotton is associated with a single begomovirus that lacks an intact transcriptional activator protein. Virus Research, 152(1-2), 153-163. https://doi.org/10.1016/j.virusres.2010.06.019

Babu, K. S. D., Manoharan, P., \& Pandi, G. (2018). Computational studies on Begomoviral AC2/C2 proteins. Bioinformation, 14(06), 294-303. https://doi.org/10.6026/97320630014294

Barh, D., Chaitankar, V., Yiannakopoulou, E. C., Salawu, E. O., Chowbina, S., Ghosh, P., \& Azevedo, V. (2013). In Silico Models: From Simple Networks to Complex Diseases. Animal Biotechnology: Models in Discovery and Translation. Elsevier. https://doi.org/10.1016/B978-0-12-416002-6.00021-3

Benkert, P., Künzli, M., \& Schwede, T. (2009). QMEAN server for protein model quality estimation. Nucleic Acids Research, 37(SUPPL. 2), 510-514. https://doi.org/10.1093/nar/gkp322

Briddon, R. W., \& Markham, P. G. (2000). Cotton leaf curl virus disease. Virus Research, 71(1-2), 151-159. https://doi.org/10.1016/s0168-1702(00)00195-7

Briddon, R. W., \& Stanley, J. (2006). Subviral agents associated with plant singlestranded DNA viruses. Virology, 344(1), 198-210. https://doi.org/10.1016/j.virol.2005.09.042

Brown, J. K., Zerbini, F. M., Navas-Castillo, J., Moriones, E., Ramos-Sobrinho, R., Silva, J. C. F., ... Varsani, A. (2015). Revision of Begomovirus taxonomy based on pairwise sequence comparisons. Archives of Virology, 160(6), 1593-1619. https://doi.org/10.1007/s00705-015-2398-y

Chatterji, A., Padidam, M., Beachy, R. N., \& Fauquet, C. M. (1999). Identification of Replication Specificity Determinants in Two Strains of Tomato Leaf Curl Virus from New Delhi. Journal of Virology, 73(7), 5481-5489. https://doi.org/10.1128/jvi.73.7.5481-5489.1999

Chen, R., \& Weng, Z. (2003). A novel shape complementarity scoring function for protein-protein docking. Proteins, 51(3), 397-408. https://doi.org/10.1002/prot.10334

Colovos, C., \& Yeates, T. O. (1993). Verification of protein structures: Patterns of nonbonded atomic interactions. Protein Science, 2(9), 1511-1519. 
597

598

599

600

601

602

603

604

605

606

607

608

609

610

611

612

613

614

615

616

617

618

619

620

621

622

623

624

625

626

627

628

629

630

631

632

633

634

635

636

637

638

639

640

641

642

https://doi.org/10.1002/pro.5560020916

DaPalma, T., Doonan, B. P., Trager, N. M., \& Kasman, L. M. (2010). A systematic approach to virus-virus interactions. Virus Research, 149(1), 1-9. https://doi.org/10.1016/j.virusres.2010.01.002

de Vries, S. J., \& Bonvin, A. M. J. J. (2011). CPORT: a consensus interface predictor and its performance in prediction-driven docking with HADDOCK. PloS One, 6(3), e17695-e17695. https://doi.org/10.1371/journal.pone.0017695

De Vries, S. J., Van Dijk, M., \& Bonvin, A. M. J. J. (2010). The HADDOCK web server for data-driven biomolecular docking. Nature Protocols, 5(5), 883-897.

https://doi.org/10.1038/nprot.2010.32

Desbiez, C., David, C., Mettouchi, A., Laufs, J., \& Gronenborn, B. (1995). Rep protein of tomato yellow leaf curl geminivirus has an ATPase activity required for viral DNA replication. Proceedings of the National Academy of Sciences of the United States of America, 92(12), 5640-5644. https://doi.org/10.1073/pnas.92.12.5640

Díaz-Muñoz, S. L. (2019). Uncovering Virus-Virus Interactions by Unifying Approaches and Harnessing High-Throughput Tools. MSystems, 4(3), 1-5. https://doi.org/10.1128/msystems.00121-19

Echave, J., Spielman, S. J., \& Wilke, C. O. (2016). Causes of evolutionary rate variation among protein sites. Nature Reviews. Genetics, 17(2), 109-121.

https://doi.org/10.1038/nrg.2015.18

Elena, S. F., Bernet, G. P., \& Carrasco, J. L. (2014). The games plant viruses play. Current Opinion in Virology, 8, 62-67. https://doi.org/10.1016/j.coviro.2014.07.003

Fauquet, C. M., Briddon, R. W., Brown, J. K., Moriones, E., Stanley, J., Zerbini, M., \& Zhou, X. (2008). Geminivirus strain demarcation and nomenclature. Archives of Virology, 153(4), 783-821.

Fondong, V. N. (2013). Geminivirus protein structure and function. Molecular Plant Pathology, 14(6), 635-649. https://doi.org/10.1111/mpp.12032

Fondong, V. N. (2019). The Ever-Expanding Role of C4/AC4 in Geminivirus Infection: Punching above Its Weight? Molecular Plant, 12(2), 145-147. https://doi.org/10.1016/j.molp.2018.12.006

Frischmuth, T., \& Stanley, J. (1998). Recombination between viral DNA and the transgenic coat protein gene of African cassava mosaic geminivirus. The Journal of General Virology, 79 ( Pt 5), 1265-1271. https://doi.org/10.1099/0022-1317-795-1265

Guerrero, J., Regedanz, E., Lu, L., Ruan, J., Bisaro, D. M., \& Sunter, G. (2020). Manipulation of the Plant Host by the Geminivirus AC2/C2 Protein, a Central Player in the Infection Cycle. Frontiers in Plant Science, 11, 591. https://doi.org/10.3389/fpls.2020.00591

Haider, M. S., Tahir, M., Latif, S., \& Briddon, R. W. (2006). First report of Tomato leaf curl New Delhi virus infecting Eclipta prostrata in Pakistan. Plant Pathology, 55(2), 285. https://doi.org/https://doi.org/10.1111/j.1365-3059.2005.01278.x

Haley, A., Zhan, X., Richardson, K., Head, K., \& Morris, B. (1992). Regulation of the activities of African cassava mosaic virus promoters by the AC1, AC2, and AC3 gene products. Virology, 188(2), 905-909. https://doi.org/10.1016/00426822(92)90551-y

Hinchliffe, A., \& Harwood, W. A. (2019). Chapter 8 Chapter 8. Test, 2012, 115-126.

Peer] reviewing PDF | (2021:02:58520:2:1:NEW 28 Jul 2021) 
643

644

645

646

647

648

649

650

651

652

653

654

655

656

657

658

659

660

661

662

663

664

665

666

667

668

669

670

671

672

673

674

675

676

677

678

679

680

681

682

683

684

685

686

687

688

https://doi.org/10.1007/978-1-4939-6798-8

Hull, R. (2014). Chapter 7 - Replication of Plant Viruses. In R. B. T.-P. V. (Fifth E. Hull (Ed.) (pp. 341-421). Boston: Academic Press.

https://doi.org/https://doi.org/10.1016/B978-0-12-384871-0.00007-8

Humphrey, W., Dalke, A., \& Schulten, K. (1996). VMD: Visual molecular dynamics. Journal of Molecular Graphics, 14(1), 33-38. https://doi.org/https://doi.org/10.1016/0263-7855(96)00018-5

Ismayil, A., Haxim, Y., Wang, Y., Li, H., Qian, L., Han, T., ... Liu, Y. (2018). Cotton Leaf Curl Multan virus C4 protein suppresses both transcriptional and posttranscriptional gene silencing by interacting with SAM synthetase. PLoS Pathogens, 14(8), e1007282-e1007282.

https://doi.org/10.1371/journal.ppat.1007282

Jyothsna, P., Haq, Q. M. I., Singh, P., Sumiya, K. V, Praveen, S., Rawat, R., ... Malathi, V. G. (2013). Infection of tomato leaf curl New Delhi virus (ToLCNDV), a bipartite begomovirus with betasatellites, results in enhanced level of helper virus components and antagonistic interaction between DNA B and betasatellites. Applied Microbiology and Biotechnology, 97(12), 5457-5471. https://doi.org/10.1007/s00253-012-4685-9

Källberg, M., Wang, H., Wang, S., Peng, J., Wang, Z., Lu, H., \& Xu, J. (2012). Template-based protein structure modeling using the RaptorX web server. Nature Protocols, 7(8), 1511-1522. https://doi.org/10.1038/nprot.2012.085

Kastritis, P. L., Moal, I. H., Hwang, H., Weng, Z., Bates, P. A., Bonvin, A. M. J. J., \& Janin, J. (2011). A structure-based benchmark for protein-protein binding affinity. Protein Science : A Publication of the Protein Society, 20(3), 482-491. https://doi.org/10.1002/pro.580

Laskowski, R., Macarthur, M. W., Moss, D. S., \& Thornton, J. (1993). PROCHECK: A program to check the stereochemical quality of protein structures. Journal of Applied Crystallography, 26, 283-291. https://doi.org/10.1107/S0021889892009944

Malik, P. S., Kumar, V., Bagewadi, B., \& Mukherjee, S. K. (2005). Interaction between coat protein and replication initiation protein of Mung bean yellow mosaic India virus might lead to control of viral DNA replication. Virology, 337(2), 273-283. https://doi.org/10.1016/j.virol.2005.04.030

Mansoor, S, Amin, I., Iram, S., Hussain, M., Zafar, Y., Malik, K. A., \& Briddon, R. W. (2003). Breakdown of resistance in cotton to cotton leaf curl disease in Pakistan. Plant Pathology, 52(6), 784. https://doi.org/10.1111/j.1365-3059.2003.00893.x

Mansoor, S, Khan, S. H., Bashir, A., Saeed, M., Zafar, Y., Malik, K. A., ... Markham, P. G. (1999). Identification of a novel circular single-stranded DNA associated with cotton leaf curl disease in Pakistan. Virology, 259(1), 190-199. https://doi.org/10.1006/viro.1999.9766

Mansoor, Shahid, Briddon, R. W., Zafar, Y., \& Stanley, J. (2003). Geminivirus disease complexes: an emerging threat. Trends in Plant Science, 8(3), 128-134. https://doi.org/https://doi.org/10.1016/S1360-1385(03)00007-4

Moreno, A. B., \& López-Moya, J. J. (2020). When viruses play team sports: Mixed infections in plants. Phytopathology, 110(1), 29-48.

https://doi.org/10.1094/PHYTO-07-19-0250-FI 
689

690

691

692

693

694

695

696

697

698

699

700

701

702

703

704

705

706

707

708

709

710

711

712

713

714

715

716

717

718

719

720

721

722

723

724

725

726

727

728

729

730

731

732

733

734

Padidam, M., Beachy, R. N., \& Fauquet, C. M. (1995). Classification and identification of geminiviruses using sequence comparisons. The Journal of General Virology, 76 ( Pt 2), 249-263. https://doi.org/10.1099/0022-1317-76-2-249

Pasumarthy, K. K., Choudhury, N. R., \& Mukherjee, S. K. (2010). Tomato leaf curl Kerala virus (ToLCKeV) AC3 protein forms a higher order oligomer and enhances ATPase activity of replication initiator protein (Rep/AC1). Virology Journal, 7(1), 128. https://doi.org/10.1186/1743-422X-7-128

Peng, J., \& Xu, J. (2009). Boosting Protein Threading Accuracy. Research in Computational Molecular Biology: ... Annual International Conference, RECOMB ... : Proceedings. RECOMB (Conference : 2005-), 5541, 31-45. https://doi.org/10.1007/978-3-642-02008-7_3

Peng, J., \& Xu, J. (2010). Low-homology protein threading. Bioinformatics, 26(12), i294-i300. https://doi.org/10.1093/bioinformatics/btq192

Pradhan, B., Vu, T., \& Mukherjee, S. (2017). Molecular Biology of Geminivirus DNA Replication. Retrieved from https://www.researchgate.net/publication/316456253

Robertson, M. J., Tirado-Rives, J., \& Jorgensen, W. L. (2015). Improved Peptide and Protein Torsional Energetics with the OPLS-AA Force Field. Journal of Chemical Theory and Computation, 11(7), 3499-3509.

https://doi.org/10.1021/acs.jctc.5b00356

Rojas, M R, Jiang, H., Salati, R., Xoconostle-Cázares, B., Sudarshana, M. R., Lucas, W. J., \& Gilbertson, R. L. (2001). Functional analysis of proteins involved in movement of the monopartite begomovirus, Tomato yellow leaf curl virus. Virology, 291(1), 110-125. https://doi.org/10.1006/viro.2001.1194

Rojas, Maria R., Noueiry, A. O., Lucas, W. J., \& Gilbertson, R. L. (1998). Bean dwarf mosaic geminivirus movement proteins recognize DNA in a form- and size-specific manner. Cell, 95(1), 105-113. https://doi.org/10.1016/S0092-8674(00)81786-9

Roy, A., Kucukural, A., \& Zhang, Y. (2010). I-TASSER: a unified platform for automated protein structure and function prediction. Nature Protocols, 5(4), 725-738. https://doi.org/10.1038/nprot.2010.5

Ruhel, R., \& Chakraborty, S. (2019). Multifunctional roles of geminivirus encoded replication initiator protein. VirusDisease, 30(1), 66-73.

Saponaro, A., Maione, V., Bonvin, A. M. J. J., \& Cantini, F. (2020). Understanding Docking Complexes of Macromolecules Using HADDOCK: The Synergy between Experimental Data and Computations. Bio-Protocol, 10(20), e3793. https://doi.org/10.21769/BioProtoc.3793

Sattar, M. Naeem, Kvarnheden, A., Saeed, M., \& Briddon, R. W. (2013). Cotton leaf curl disease - An emerging threat to cotton production worldwide. Journal of General Virology, 94(PART4), 695-710. https://doi.org/10.1099/vir.0.049627-0

Sattar, M Naeem, Kvarnheden, A., Saeed, M., \& Briddon, R. W. (2013). Cotton leaf curl disease - an emerging threat to cotton production worldwide. The Journal of General Virology, 94(Pt 4), 695-710. https://doi.org/10.1099/vir.0.049627-0

Sattar, Muhammad N, Iqbal, Z., Tahir, M. N., \& Ullah, S. (2017). The Prediction of a New CLCuD Epidemic in the Old World. Frontiers in Microbiology, 8, 631. https://doi.org/10.3389/fmicb.2017.00631

Schrödinger. (n.d.). pymol. Retrieved from The PyMOL Molecular Graphics System, Version 2.0 Schrödinger, LLC.

Peer) reviewing PDF | (2021:02:58520:2:1:NEW 28 Jul 2021) 
735

736

737

738

739

740

741

742

743

744

745

746

747

748

749

750

751

752

753

754

755

756

757

758

759

760

761

762

763

764

765

766

767

768

769

770

771

772

773

774

775

776

777

778

779

780

Settlage, S. B., See, R. G., \& Hanley-Bowdoin, L. (2005a). Geminivirus C3 Protein: Replication Enhancement and Protein Interactions. Journal of Virology, 79(15), 9885-9895. https://doi.org/10.1128/jvi.79.15.9885-9895.2005

Settlage, S. B., See, R. G., \& Hanley-Bowdoin, L. (2005b). Geminivirus C3 Protein: Replication Enhancement and Protein Interactions. Journal of Virology, 79(15), 9885-9895. https://doi.org/10.1128/JVI.79.15.9885-9895.2005

Studer, G., Rempfer, C., Waterhouse, A. M., Gumienny, R., Haas, J., \& Schwede, T. (2020). QMEANDisCo-distance constraints applied on model quality estimation. Bioinformatics (Oxford, England), 36(6), 1765-1771. https://doi.org/10.1093/bioinformatics/btz828

Syller, J., \& Grupa, A. (2016). Antagonistic within-host interactions between plant viruses: molecular basis and impact on viral and host fitness. Molecular Plant Pathology, 17(5), 769-782. https://doi.org/https://doi.org/10.1111/mpp.12322

van Zundert, G. C. P., Rodrigues, J. P. G. L. M., Trellet, M., Schmitz, C., Kastritis, P. L., Karaca, E., ... Bonvin, A. M. J. J. (2016). The HADDOCK2.2 Web Server: UserFriendly Integrative Modeling of Biomolecular Complexes. Journal of Molecular Biology, 428(4), 720-725. https://doi.org/10.1016/j.jmb.2015.09.014

Van Zundert, G. C. P., Rodrigues, J. P. G. L. M., Trellet, M., Schmitz, C., Kastritis, P. L., Karaca, E., ... Bonvin, A. M. J. J. (2016). The HADDOCK2.2 Web Server: UserFriendly Integrative Modeling of Biomolecular Complexes. Journal of Molecular Biology, 428(4), 720-725. https://doi.org/10.1016/j.jmb.2015.09.014

Vangone, A., \& Bonvin, A. M. J. J. (2015). Contacts-based prediction of binding affinity in protein-protein complexes. ELife, 4, e07454. https://doi.org/10.7554/eLife.07454

Vangone, A., \& Bonvin, A. M. J. J. (2017). PRODIGY: A Contact-based Predictor of Binding Affinity in Protein-protein Complexes. Bio-Protocol, 7(3), e2124. https://doi.org/10.21769/BioProtoc.2124

Varsani, A., Roumagnac, P., Fuchs, M., Navas-Castillo, J., Moriones, E., Idris, A., ... Martin, D. P. (2017). Capulavirus and Grablovirus: two new genera in the family Geminiviridae. Archives of Virology, 162(6), 1819-1831. https://doi.org/10.1007/s00705-017-3268-6

Wang, S. H., Wu, T. J., Lee, C. W., \& Yu, J. (2020). Dissecting the conformation of glycans and their interactions with proteins. Journal of Biomedical Science, 27(1), 1-16. https://doi.org/10.1186/s12929-020-00684-5

Waterhouse, A. M., Procter, J. B., Martin, D. M. A., Clamp, M., \& Barton, G. J. (2009). Jalview Version 2-a multiple sequence alignment editor and analysis workbench. Bioinformatics, 25(9), 1189-1191. https://doi.org/10.1093/bioinformatics/btp033

Webb, B., \& Sali, A. (2014). Comparative protein structure modeling using MODELLER. Current Protocols in Bioinformatics (Vol. 2014). https://doi.org/10.1002/0471250953.bi0506s47

Wiederstein, M., \& Sippl, M. J. (2007). ProSA-web: Interactive web service for the recognition of errors in three-dimensional structures of proteins. Nucleic Acids Research, 35(SUPPL.2), 407-410. https://doi.org/10.1093/nar/gkm290

Wu, S., \& Zhang, Y. (2007). LOMETS: A local meta-threading-server for protein structure prediction. Nucleic Acids Research, 35(10), 3375-3382. https://doi.org/10.1093/nar/gkm251

Wu, Y., Tepper, H. L., \& Voth, G. A. (2006). Flexible simple point-charge water model

Peerj reviewing PDF | (2021:02:58520:2:1:NEW 28 Jul 2021) 
781 with improved liquid-state properties. The Journal of Chemical Physics, 124(2), 24503. https://doi.org/10.1063/1.2136877

Xu, D., \& Zhang, Y. (2013). Toward optimal fragment generations for ab initio protein structure assembly. Proteins: Structure, Function, and Bioinformatics, 81(2), 229239. https://doi.org/https://doi.org/10.1002/prot.24179

Yang, J., \& Zhang, Y. (2015). I-TASSER server: new development for protein structure and function predictions. Nucleic Acids Research, 43(W1), W174-W181. https://doi.org/10.1093/nar/gkv342

Yang, X., Baliji, S., Buchmann, R. C., Wang, H., Lindbo, J. A., Sunter, G., \& Bisaro, D. M. (2007). Functional Modulation of the Geminivirus AL2 Transcription Factor and Silencing Suppressor by Self-Interaction. Journal of Virology, 81(21), 11972 LP _ 11981. https://doi.org/10.1128/JVI.00617-07

Zaidi, S. S. E. A., Martin, D. P., Amin, I., Farooq, M., \& Mansoor, S. (2017). Tomato leaf curl New Delhi virus: a widespread bipartite begomovirus in the territory of monopartite begomoviruses. Molecular Plant Pathology, 18(7), 901-911. https://doi.org/10.1111/mpp.12481

Zaidi, S. S. E. A., Shafiq, M., Amin, I., Scheffler, B. E., Scheffler, J. A., Briddon, R. W., \& Mansoor, S. (2016). Frequent occurrence of tomato leaf curl New Delhi virus in cotton leaf curl disease affected cotton in Pakistan. PLoS ONE, 11(5), 1-15. https://doi.org/10.1371/journal.pone.0155520

Zhang, S. C., Wege, C., \& Jeske, H. (2001). Movement proteins (BC1 and BV1) of Abutilon mosaic geminivirus are cotransported in and between cells of sink but not of source leaves as detected by green fluorescent protein tagging. Virology, 290(2), 249-260. https://doi.org/10.1006/viro.2001.1185

Zubair, M., Zaidi, S. S.-E.-A., Shakir, S., Amin, I., \& Mansoor, S. (2017). An Insight into Cotton Leaf Curl Multan Betasatellite, the Most Important Component of Cotton Leaf Curl Disease Complex. Viruses, 9(10). https://doi.org/10.3390/v9100280 


\section{Figure 1}

\section{Begomovirus genome and domain organisation of different viral proteins}

Monopartite genome is represented by CLCuKoV-Bu and Bipartite genome is represented by ToLCNDV. Domain organisation of different proteins consists of: A) Replication Initiation Protein (Rep) DNA Nicking Domain (amino acids 1-120), DNA Binding Domain (amino acids 1-130) and the Oligomerization domains (amino acids 120-182) (B) Transcription Activation Protein (TrAP) (this protein maybe truncated ( $35 \mathrm{aa})$ in case of CLCUKoV-Bu or complete ( 134 aa) in case of ToLCNDV. The first 35 aa are similar are form similar domains, in both the cases, the protein consists of a basic region along with a potential nuclear localization sequence (NLS region; amino acids 17-31), Zinc finger region (ZFD; amino acids 33-55) Programmed cell death (PCD region; amino acids 20-55) (C) Replication Enhancer Protein (REn) consists of $p R B R$ binding domains (pPBR-A; amino acids 1-13) (pPBR-B; amino acids 125-134), the PCNA binding domain, REn oligomerization domain (amino acid 28-128), Rep interacting domain (amino acid 28-128) along with three hydrophobic clusters (amino acids 18-28, 60-70, 80-110) (D) C4/AC4 protein of monopartite and bipartite viruses vary in size, the protein generally consists of $\mathrm{N}$-terminal myristoylation motif (amino acids 1-18), Sadenosyl Methionine Synthetase Interacting Domain (amino acid 13), SHAGGY like Kinase interacting Domain (amino acids 30-56) and Nuclear Export Sequence (NES; amino acids 65-81) (E) Coat Protein (CP) consists of The Nuclear Localization Sequences (amino acids 1-54, 100-127, 201-258) DNA binding domain (amino acid 1-121) Cell wall targeting domain (CW; amino acids 100-127). (F) V2/AV2 Protein consists of Putative Protein Kinase C (PKC) phosphorylation motif (amino acids 40-42), WCCH domain (amino acids 79-94) in the protein (G) Movement Protein (MP) consists of a pilot domain (amino acids 1-49), an anchor domain (amino acids 117-160) and an oligomerization domain amino (acids 161-250) (H) Nuclear Shuttle Protein (NSP) consists of an NLS-A (amino acids 21-42), NLS-B (amino acids 81-96), a DNA binding region (amino acids 39-109), MP interacting Domain (amino acids 200-254), Nuclear Export Signal (NES; (amino acids 112 184-194),) and AtNSI Interacting Domain (amino acids 109-184) (I) CLCuMB $\beta C 1$ protein consists of a myristoylation like motif (amino acids 101-108) 

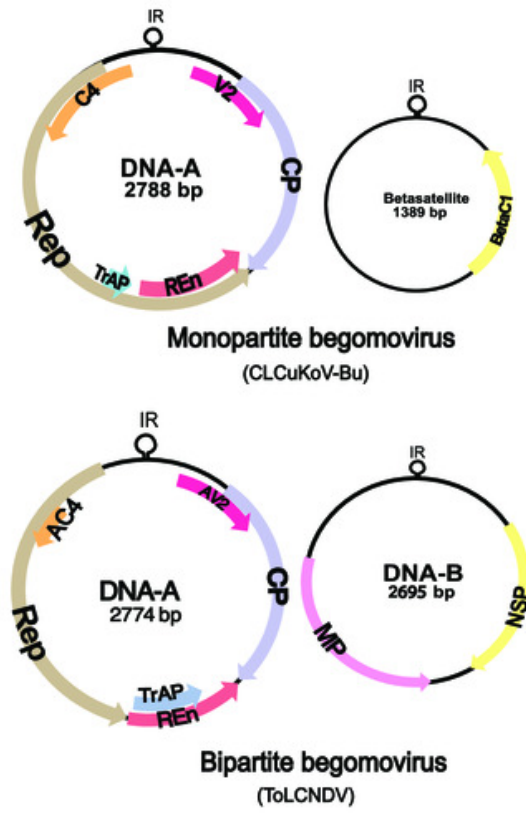
(TOLCNDV)
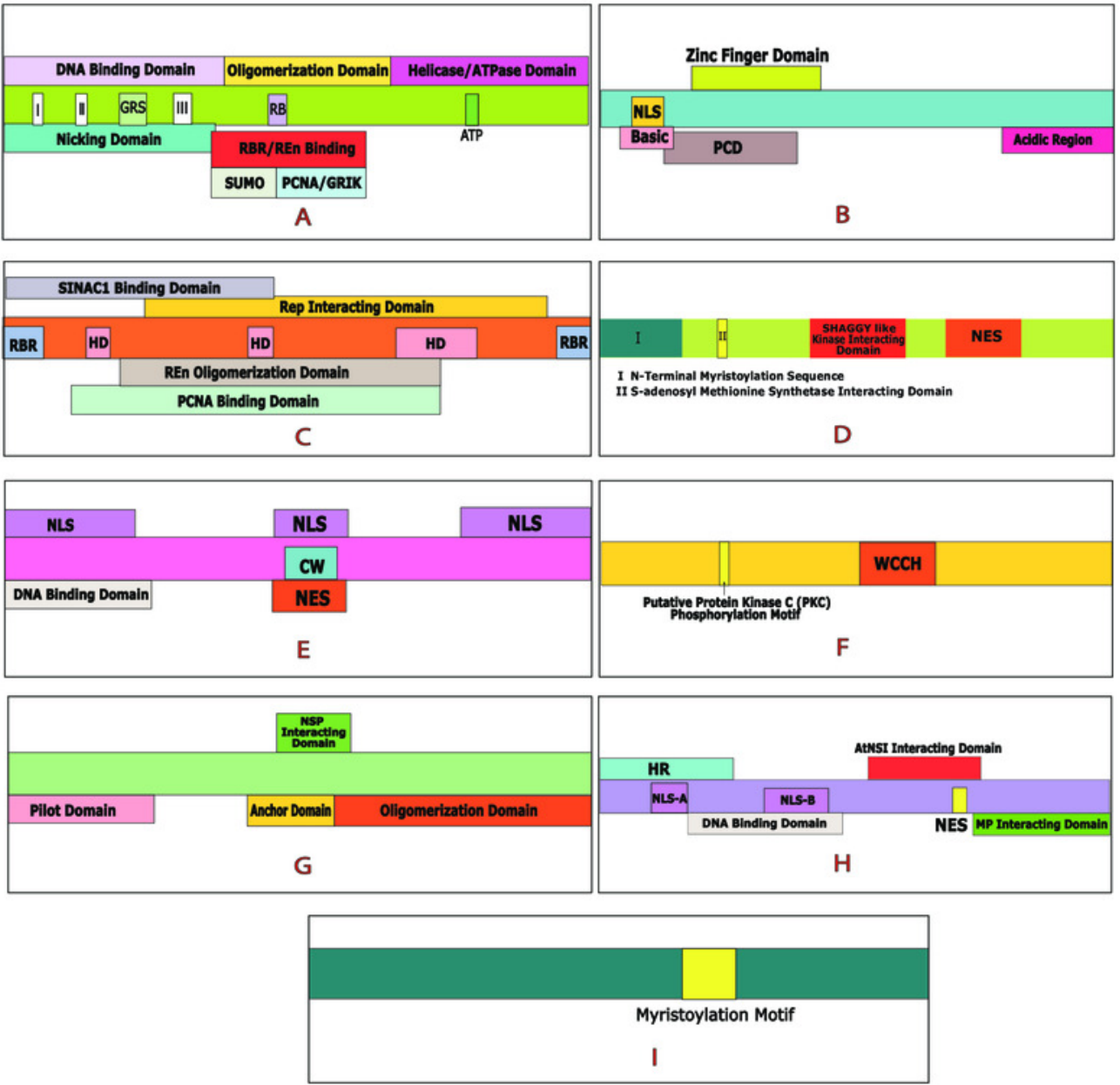
Figure 2

Consensus Models of the proteins of CLCuKoV-Bu and ToLCNDV generated through different approaches are presented.
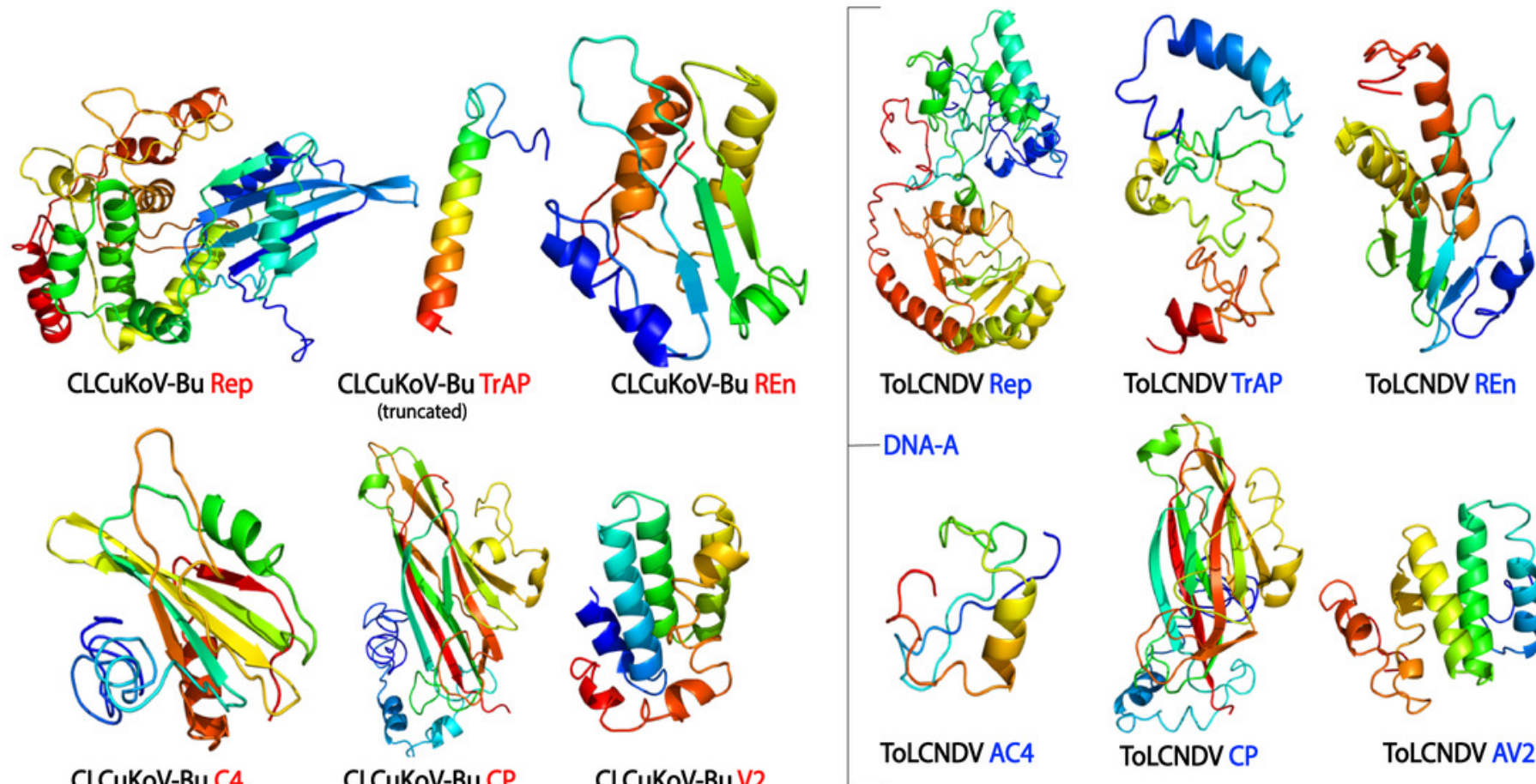

ToLCNDV Rep

ToLCNDVTrAP

TOLCNDV REn

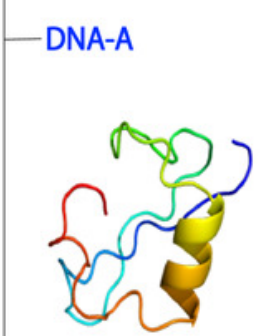

ToLCNDV AC4

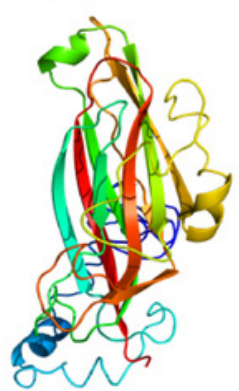

ToLCNDV CP

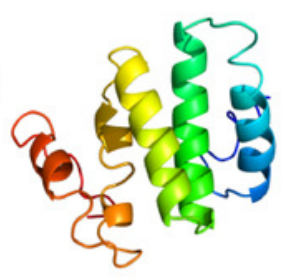

ToLCNDV AV2
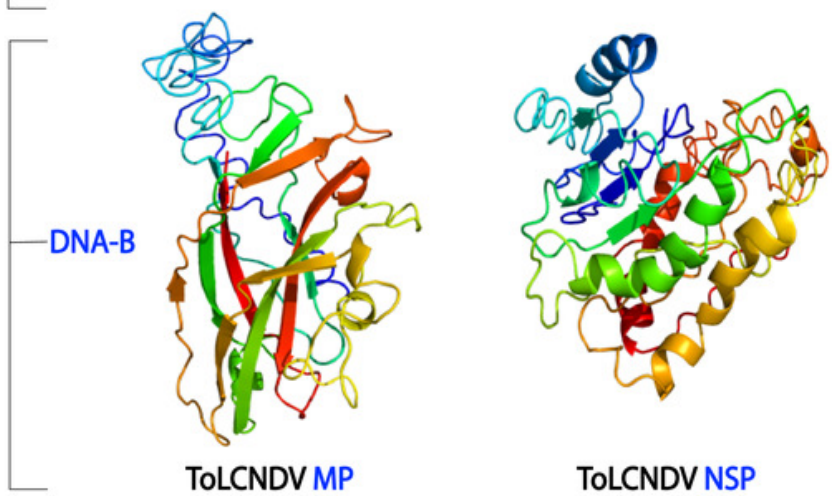

ToLCNDV NSP 


\section{Figure 3}

HADDOCK provided scores for some of the strongest observed interactions

(A) Scores of Clusters 1-7 for PPI of Rep (CLCuKoV-Bu) with MP (ToLCNDV): The complex had the HADDOCK scores of -279.8, -259.2, -238.3, -237.5, -235.9, -233.1, -216.9.; Desolvation energy in ( $\mathrm{kcal} / \mathrm{mol})$ -125.7, -110.9, -131.3, -122.1 , -139.1, -128.2 ; Van Der Waals energy values of -120.5, -125, -114.4, -110.1, -106, -106.8, -83.5; Restraints Violation Energy values of 523, 514, 586.2, 605.1, 534.1, 530.1, 605.1; ZScore of $-2,-1.2,-0.3,-0.3,-1.2,-0.1,0.6$; Cluster size of $47,7,9,26,14,14,5$; RMSD (A) values of 10.6, 13.4, $1.8,6.2,4.7,4.1,11.8 ;$ Buried surface area of 3939, 3636, 3470, 3417, 3034, 3091, 3478 and Electrostatic Energy of -429.9, -373.3, -255.8, -329.4, -220.5, -255.4, -240. (B) Scores of Clusters 1-7 for PPI of Rep (CLCuKoV-Bu) with NSP (ToLCNDV): The complex had the HADDOCK scores of -241.5, -223.4, -221.7, -217.8, -211.9, -211.4,-198.3 ; Desolvation energy in ( $\mathrm{kcal} / \mathrm{mol})-144,-144,-150.3,-124.3,-140.8,-157.1$, -140.4; Van Der Waals energy values of -130.1, 115, -107.1, -114.5, -107.5, -108.7, -101.4; Restraints Violation Energy values of 721.5, 789.7, 906.7, 877.9, 736.3, 933, 758.6; Z-Score of -2.1, -0.8, -0.7, -0.5, $-0.1,0,0.9$; Cluster size of 24, 17, 35, 8, 13, 10, 6; RMSD ( $\AA$ ) values of 13.1, 14.9, 18.1, 2.1,18.5,6.3,14.3 ; Buried surface area of 3733.4, 3345.7, 2960.4, 3677.7, 2983.7, 2939.2, 3116.5 and electrostatic energy of -197.9, -216.8, -275.1, -333.8, -185.8,-194.3,-161.1. (C) Scores of Clusters 1-7 for the PPI of REn (CLCuKoV-Bu) - NSP (ToLCNDV) : The complex had the HADDOCK scores of -217.8, -198, -85, -50, -49.9,-35.4,-35.1; Desolvation energy in ( $\mathrm{kcal} / \mathrm{mol}),-124.3,-140,-46.6,-72.4,-78.8,-72.4,-65.3$; Van Der waals energy values $-114.5,-101.5,-115.7,-99.5,-100,-70.8,-236$; Restraints Violation Energy values of 1877, 1646, 1703. 1419, 1588, 1724, 1654; Z-Score of 0.1, 0.5, -2.6, -0.6, -0.6, 0.3, 0.5; Cluster size of 8, 6, $16,9,7,8,5 ;$ RMSD $(\AA)$ values of $2.1,14.3,7,10.8,12,16.3,15.6$; Buried surface area of 2889.2, 2732.7, $2756.8,2188.6,2513.2,2409.6,2377.6$ and electrostatic energy of $-220,-172.9,-186.4,-163.8,-175.8$, -170.8, -161.3. (D) Scores of Clusters 1-7 for the PPI of Rep (CLCUKoV-Bu) with Rep (ToLCNDV): The complex had the HADDOCK scores of -199.9, -136, -201, -162.8, -124.4,-186.7,-95; Desolvation energy in $(\mathrm{kcal} / \mathrm{mol})-159,-165.5,-133.8,-148.6,-158.6,-157.2,-152.8$; Van Der waals energy values -138.9, $-145.4,-121.3,-94.6,-114.3,-117.9,-102$; Restraints Violation Energy values of 1541, 1817.2, 1869.5, 1390, 1779.3, 1510.2, 2001.9; Z-Score of -1.4, 0.5, -1.4, -0.3, 0.8, -1, 1.7; Cluster size of 10, 33, 11, 8, 6, 6, 5; RMSD $(\AA)$ values of $25.3,9.2,14.6,4.4,19.6,1,25.1$; Buried surface area of $33825.9,3552.4,3927.4$, 2922.9, 3310.6, 3678.1, 3039.4 and Electrostatic Energy of -215.3,-313.1, -450.1, -293.2,-146.9, -313.1, -202.1 .

Peer] reviewing PDF | (2021:02:58520:2:1:NEW 28 Jul 2021) 

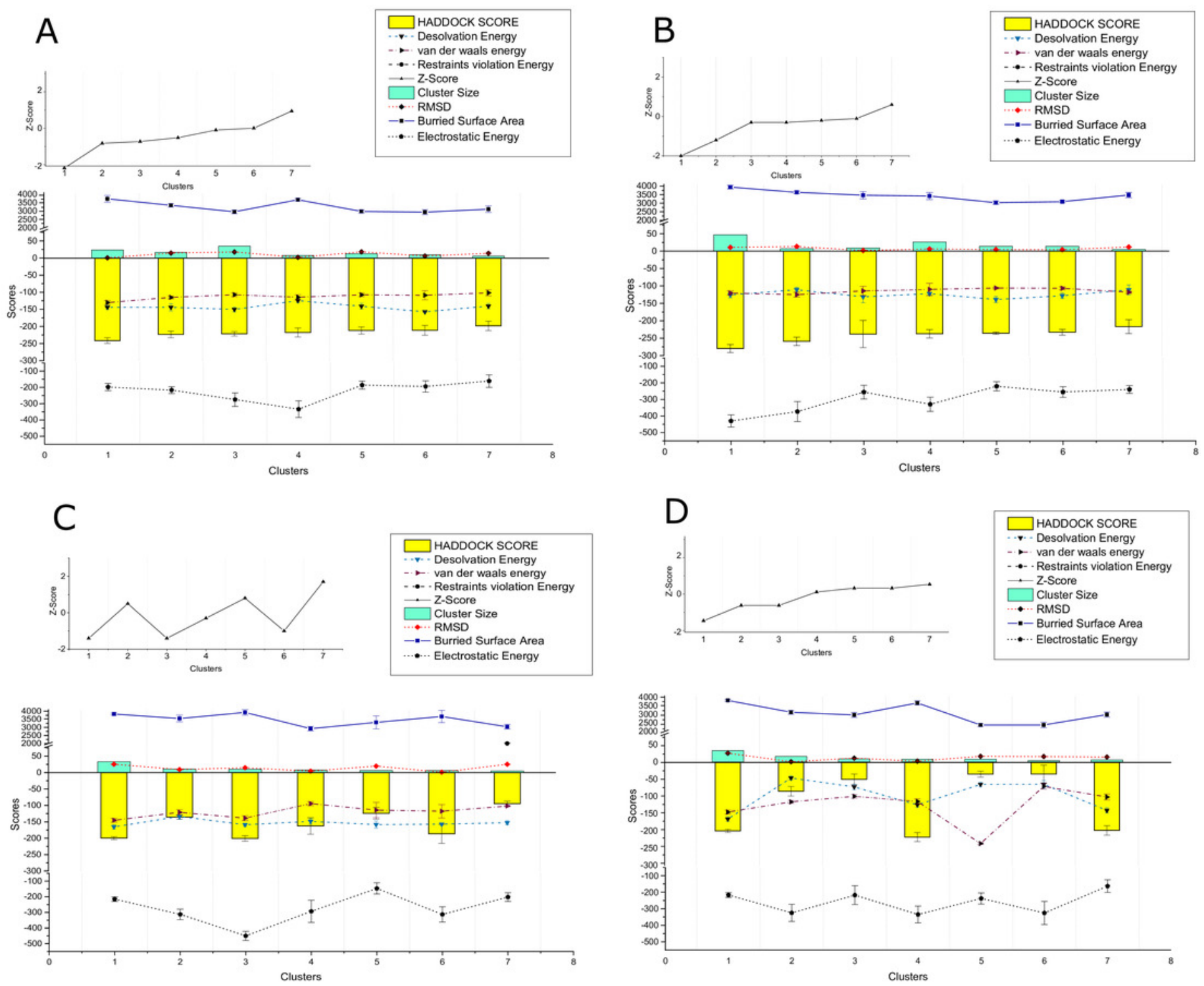


\section{Figure 4}

Identification of the amino acid residues taking part in interaction in Rep, TrAP and REn proteins of both CLCuKoV-Bu and ToLCNDV

(A) Rep protein, CLCuKoV-Bu (top,1-363 amino acids) and ToLCNDV (bottom,1-358 amino acids). The Rep protein consists of DNA- Nicking domain 1-120, DNA Binding Domain (1-130), oligomerization domain (amino acids 120-182) at the $\mathrm{N}$-terminal while the $\mathrm{C}$ terminal consists of ATPase/Helicase domain. The $39^{\text {th }}$ amino acid from the Nicking/ DNA binding domain is involved in the interaction with the majority of the interacting residues occurring in the ATPase/Helicase domain. (B) TrAP protein, CLCuKoV-Bu (top, 1-35 amino acids) and ToLCNDV (bottom,1-139 amino acids). The residues from the NLS domain ( amino acids 20-30) are taking part in interaction for the TrAP of CLCuKoV-Bur while for the TrAP of ToLCNDV the residues from the NLS, ZFD ( amino acids 33-55), and PCD ( amino acids 20-55) domain were involved in interaction. (C) REn protein, CLCuKoV-Bu (top,1-134 amino acids) and ToLCNDV (bottom,1-136 amino acids). The interacting residues for REn protein of both the viruses occurs in the RBR ( amino acids 1-8) domain, REn oligomerization domain ( amino acids 28-95), PCNA binding domain ( amino acids 7-95), SINACl domain ( amino acids 1-80). 


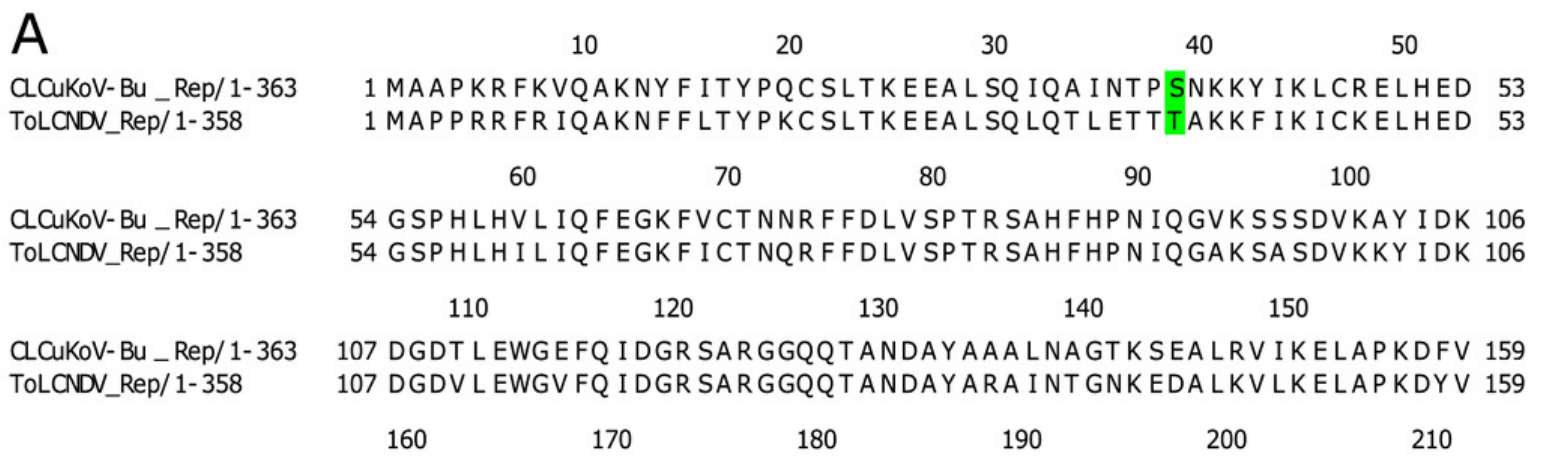

QCuKoV-Bu_Rep/1-363 ToLCNDV_Rep/1-358

160 LQFHNLNANLDR I FQEPPAPY I SP F SP SSFDQVPEELEVWA I DNVVDAAARPL 212 160 LQ FHNMN SN LDR I FPPRAEVYVSPFS I SSFDRVPQELVDWV SGNVGCSAARP I 212

$$
220 \quad 230 \quad 240 \quad 250 \quad 260
$$

Q. QuKoV-Bu_Rep/1-363 TOLCNDV_Rep/1-358

213 RPR S IV I EGDSRT GKTMWAR SLGPHNY LCGHLDL SPKVY SNDAWY NV I DDVDP 265 213 RP I G IV I EGD SRT GKT AWAR SLGPHNY LCGHLDLSPRVYNNDAWY NV I DDVDP 265

$$
270 \quad 280 \quad 300 \quad 310
$$

QCaKoV-Bu_Rep/1-363 266 HFLKHFKEFMGAQRDWQ SNTKY GKPVQ IKGG IPT I F LCNPGPNSSYKEF IDEE 318 ToLCNDV_Rep/ $1-358$ 266 HY LKHFKEFMGAQRDWQ SNTKY GKPVM IKGG I P I F LCNKGP N SSYKEY LDEE 318

$\begin{array}{lllll}320 & 330 & 340 & 350 & 360\end{array}$

QCuKoV-Bu_Rep/1-363 ToLCNDV_Rep/ $1-358$

B
10
20
30
40
50

CLCuKoV- Bu TrAP/ 1- 35 TLCNDV_Tr AP/ 1- 139

MQ SSSL SKDHCTQ LP I KVQHREAKRRNRRRRVD I E.... 1 MQ SLSHSKNHSI PVAKT SLPQKKKKSIRRRRVDLQCGCTYYCSIHCHDHGFTH 53 60 70 80 100

CLCuKoV-Bu TrAP/1-35 TLCNDV_Tr AP/ 1- 139 54 RGVHHCGSSR EWR I Y LGNSK SPVFQNFETQQQT LPKTARHHQY SNT I QPQPAE 106

110 120 130

CLCuKoV-Bu TrAP/ 1- 35

TLCNDV_TrAP/ $1-139$

\section{$\begin{array}{lllll}10 & 20 & 30 & 40 & 50\end{array}$}

QCuKoV-Bu_REn/1-134 1 MDSRTGEP ITAAQAGNGAY IWEVPNPLYFK I I SHVNRPFTTNMDILT IR IQFN 53 TOLCNDV_REn/1-136 1 MITDSRTGEYITADRTESGVYTWE IRNPLYFK I LKHDSRPFLTQHDIIKIQIQ 53
60
70
80
90
100

QCuKoV-Bu_REn/1-134 54 HNLRKALG I HKCF I A FR I WMT SQPPT DRFLRVFRTQVLKY LNNLG IVS INNVV 106 ToLCNDV_REn/1-136 54 FNHNLRKA LGLHKCFLTFK IWT GLRPQ I G I F LRVFKTQV LKYLDMLGV I G IYN 106

110 120

130

QCCKKoV-Bu_REn/1-134 107 RAVDHVLWNVLQHVVFVDQSSS IK FN IY - ToLCNDV_REn/1-136 107 V I RA VYHV LDNV LERT I DVQT SYDIKLDIY 


\section{Figure 5}

Identification of the amino acid residues taking part in interaction in C4, CP and V2 proteins of both CLCUKoV-Bu and ToLCNDV

(A) C4 protein of CLCuKoV-Bu (top, 1-146 amino acids) and AC4 ToLCNDV (bottom, 1-58 amino acids). The interacting residues for C4/AC4 protein of the viruses occur in the $\mathrm{N}$-terminal myristoylation sequence (1-8 amino acids), the S-adenyl methionine synthetase interacting residue (13th residue) and the SHAGGY-like Kinase interacting domain (51st residue). No residue from the nuclear export signal NES (65-81 amino acids) domain was involved. (B) CP of CLCUKoV-Bu (top, 1-256 amino acids) and ToLCNDV (bottom, 1-256) amino acids. The interacting residues occur in the NLS (1-54 amino acids) and the NES/CW (100-127 amino acids) domains. Some residues also occur in the NLS domain at the C terminal. (C) V2 protein of CLCuKoV-Bu (top, 1-118 amino acids) and AV2 ToLCNDV (bottom, 1-112 amino acids). The V2 protein of CLCUKoV-Bu has residues in the PKC phosphorylation motif (40-42 amino acids) and the WCCH domain (79-94 amino acids) while for AV2 of ToLCNDV only the residues in the WCCH domain took part in interaction. 
A

CLCuKoV-Bur_C4/ 1- 146 TOLCNDV_AC4/ 1- 58

CLCuKoV- Bur C4/ 1- 146

TOLCNDV_AC4/ 1- 58

10

20

30

40

50

1 MPFGDT I NC I QSP I RRVKAHQ LSLIDQ SQWLPPNVLKYKAKII SSLIHSAHSL 53 1 MGLR I SMF SSNSKGNSSAK I TDSSTWFPQVGQH I SIRT FRELNQRQMSKHTST 53

60

70

80

90

100

54 KRKHFPKFKPSTRPR I KNT SN SAESYTKMGAL I SMC SSSSRANSSAQ I TDSST 106

54 KTETF. . . . . . . . . . . . . . . . . . . . . . 58

$110 \quad 120 \quad 130 \quad 140$

CLCuKoV-Bu_C4/1-146107 WY PQPGQH I S I RT FRELLNQAQM SRPT STRTGT LSSGESFR

146

TOLCNDV_AC4/ 1- 58

10

20

30

40

50

CLCuKoV-Bu_CP/ 1- 256

TOLCNDV_CP/ $1-256$

1 MSKRPADI I I STPASKVRRRLNFDSPYVSRAAAP IVRVTKAKAWANRPMNRKP 53 1 MAKRPAD I I I STPASKVRRRLNFDSPYGARAVVP I ARVTKAKAWT NRPMNRKP 53

60 70

80

90

100

CLCuKoV-Bu_CP/1-256 54 RMYRMYRSPDVPRGCEGPCKVQSFESRHDIQHIGKVMCVSDVTRGTGLTHRVG 106 TOLCNDV_CP/ $1-256$ 54 RMYRKSCSPDVPRGCEGPCKVQ SFESRHDV SH I GKVMCV SDVTRGT GLTHRVG 106

$110 \quad 120 \quad 130 \quad 140 \quad 150$

CLCuKoV-Bu_CP/1-256 107 KRFCVKSVYVLGK I WMDEN I KT KNHTNSVMFFLVRDRRPVDKPQDFGEVFNMF 159 TOLCNDV_CP/ $1-256$ 107 KRFCVK SVYVLGK I WMDEN I KTKNHTN SVMFF LVRDRRPT GSPQDFGEVFNMF 159

160 170 180 190 200 210

CLCuKoV-Bu_CP/1-256 160 DNEPSTATVKNVHRDRYQVLRKWYATVTGGQYA SKEQALVKKF IRVNNYVVYN 212 TOLCNDV_CP/ 1- 256 160 DNEP STAP VKNMHRDRYQV LRKWHATVTGGTYA SWEQALVRKFVRVYNYVVYN 212

$220 \quad 230 \quad 240 \quad 250$

CLCUKoV-BU_CP/1-256 213 QQEAGKYENHSENALMLYMACTHASNPVYATLKIRIYFYDSVTN TOLCNDV_CP/ 1- 256 213 QQ EAGKYENHT ENA LMLYMARTHASNPPYATLK I P I SFYDSVTN

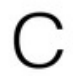

10

20

30

40

50

CLCuKoV-Bu_V2/1-118 TOLCNDV_AV $2 / 1-112$

MWDP LLNEFPDTVHGFR CM LAVKY LQLVEKTY SPDT LGYDL IRDLILVIRARN 53 1 MWDPLLHEFPESVHGLRCMLAVKYLQEIEKTY SPDTVGYDLVRDLIFVLRSKN 53
60
70
80
90
100

QCUKoV-Bu_V2/1-118 54 YVEAT SRYNHFHARFEGTPP SQ LRQP ICEPCCCPHCPRHQSK SMGEQAHEQKA 106 TOLCNDV_AV2/1-112 54 Y VEAT SRYHHFNTR I EGTPT AQ LRQP LWNT C LCPHCPRHKSKGLDEQAHEQKT 106 110 


\section{Figure 6}

Identification of the amino acid residues taking part in interaction in $\beta C 1$ of $C L C u M u B$ and MP and NSP of ToLCNDV

(A) $\beta C 1$ protein of CLCUMUB. The residues from the myristoylation like motif domain (101-108 amino acids) were involved in the interaction. (B) MP protein from DNA-B of ToLCNDV. The residues from the pilot domain (1-49 amino acids ), Anchor domain (117-160 amino acids) and the Oligomerization domain (161-250 amino acids) to be involved in interaction. The residues from the NSP interacting domain may also be involved in the interactions. (C) NSP protein from DNA-B of ToLCNDV. The residues from the NLS (21-42 amino acids), DNA Binding domain (39-109 amino acids), MP interacting domain (200-254 amino acids), and the AtNSI interacting domain (109-184 amino acids), no residues from the NES domain (184-194 amino acids) took part in the interactions. 
A

CLCuMuB_BCl/ 1- 118

CLCuM
$\square$

ToLCNDV_MP/1- 281

ToLCNDV_MP/1-281

ToLCNDV_MP/1- 281

ToLCNDV_MP/1-281

ToLCNDV_MP/1-281

ToLCNDV_MP/1-281

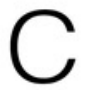

ToLCNDV_NSP/1- 267

ToLCNDV_NSP/1- 267

TOLCNDV_NSP/1- 267

ToLCNDV_NSP/1-267

ToLCNDV_NSP/1- 267

ToLCNDV_NSP/1- 267

10

20

30

40

50

1 MTT SGT NKEGVRF I VDVR I MENMK I F I HMR I LSTKSPSL I KYEG IVOYTYEDI 53

60

$\stackrel{80}{1}$

90

100

70

RLDILVLENPE।

I LGMDV 106 110

118107 IEPY, FNKKFTV

118

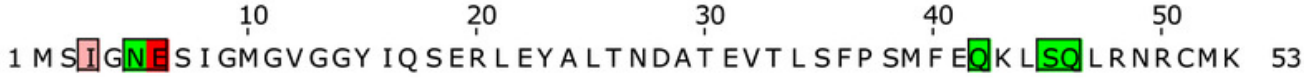
$\begin{array}{lllll}60 & 70 & 80 & 90 & 100\end{array}$

54 I DHVVLEYR SQVP INAVGHVV I E IHDMRLTEGDT KQAEFT IP I KCNCNLHYYY 106

$\begin{array}{llll}110 & 120 & 130 & 140\end{array}$

107 SSFF SLKDKNPWR VEYRIVENANVVNGVHFCKMLGK LKLSSAKHSTDVEFRPPK 159

$\begin{array}{lllll}160 & 170 & 180 & 190 & 200\end{array}$

160 I E IQTTKEFT VNDIDDFWSVGSKPQTRRLVDG SR LMGHSSR SLRVPYMA I GPINES 212

$220230250 \quad 230 \quad 260$

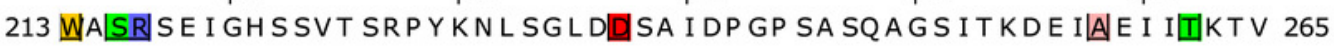
$270 \quad 280$

266 EQC I圆SNVINAIPLSK GV

281

1 MAFP SPHATPR RSGYP SNRTYNGNRSFR LW KSRK SQNWKRYRSTHPT SR SPTE 53

$\begin{array}{lllll}60 & 70 & 80 & 90 & 100\end{array}$

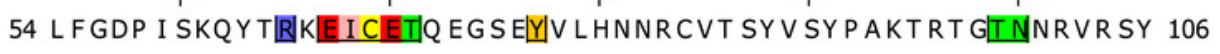

$\begin{array}{llll}110 & 120 & 130 & 140\end{array}$

107 I K L NN LNI SGTFAVRT SDMMTIGV GQ

$\begin{array}{lllll}160 & 170 & 180 & 190 & 200\end{array}$

160 PFVELFGSVNACRGRVKVAERHHERFVLLNQT SIVVNTPHSNA I KKFCIRNA I 212

$\begin{array}{llll}220 & 230 & 240 & 250\end{array}$

213 PRTYTTWVTT FKDEEED SCT GRY SNT LRNA I I LYYVWL SDVP SQVDDLIY|S|NV I L LIN 265

266 Y I

267 
Figure 7

50 ns MD simulation analysis for Complex 1 Rep (CLCUKoV-Bu) and MP (ToLCNDV) and Complex 2 Rep (CLCUKoV-Bu) and NSP (ToLCNDV)

(A) RMSD: Complex 1 had the lower RMSD as compared to complex 2, average value of RMSD for complex 1 was 0.45 and 0.65 for complex 2. (B) RMSF: The average value of RMSF for complex 1 is 0.75 for complex 2 it is 0.675 (C) Radius of Gyration (Rg):. The average value of $R_{g}$ was 2.66 for complex 1 and 2.825 for complex 2 during the 50 ns simulation (D) H-Bond Analysis: The complexes are stable due to high number of hydrogen bonds present

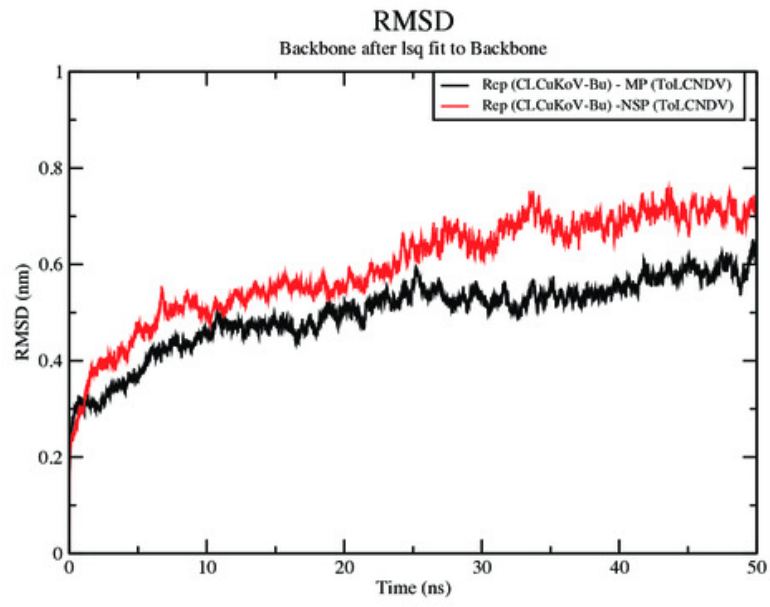

Radius of gyration (total and around axes)

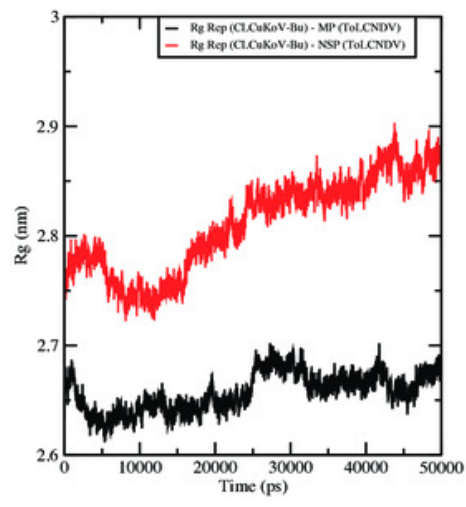

RMS fluctuation

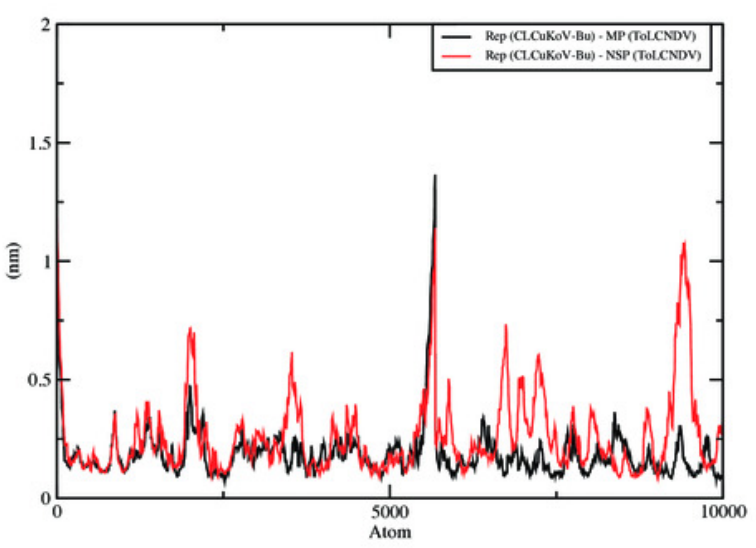

Molecule 0, md_0_1.gro: H-Bonds vs. Frame

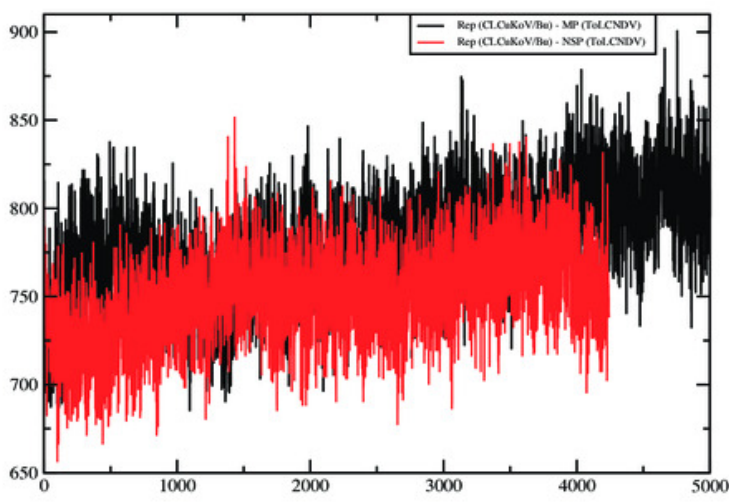




\section{Table $\mathbf{1}$ (on next page)}

Sequence Retrieval and PSI-BLAST result for Genes for DNA-A CLCuKoV-Bur, $\beta C 1$ gene of CLCUMB and DNA-A and DNA-B of ToLCNDV 
1 Table 1:

2 Sequence Retrieval and PSI-BLAST result for Genes for DNA-A CLCuKoV-Bur, $\beta C 1$ gene 3 of CLCuMB and DNA-A and DNA- B of ToLCNDV

4

\begin{tabular}{|c|c|c|c|c|c|c|c|}
\hline \multirow[b]{2}{*}{ Virus } & \multirow{2}{*}{\multicolumn{2}{|c|}{ Uniprot Accession No. }} & \multicolumn{5}{|c|}{ PSI- BLAST Result } \\
\hline & & & \multirow{2}{*}{$\begin{array}{c}\text { PDB ID } \\
\text { 1L2M }\end{array}$} & \multirow{2}{*}{$\begin{array}{r}\text { Total } \\
\text { Score }\end{array}$} & \multirow{2}{*}{$\begin{array}{l}\text { Query } \\
\text { Cover } \\
31 \%\end{array}$} & \multirow{2}{*}{$\begin{array}{l}\text { E value } \\
2 \mathrm{e}-66\end{array}$} & \multirow{2}{*}{$\begin{array}{c}\text { Percentage } \\
\text { Identity }\end{array}$} \\
\hline \multirow{6}{*}{$\begin{array}{c}\text { CLCuKoV- } \\
\text { Bur }\end{array}$} & Rep & A0A0S2MSV0 & & & & & \\
\hline & TrAP & A0A0S2MST9 & 6DDT & 24.6 & $48 \%$ & $52.94 \%$ & $52.94 \%$ \\
\hline & REn & A0A0S2MSU6 & $2 \mathrm{XF} 4$ & 32.7 & $44 \%$ & 0.1 & $30.16 \%$ \\
\hline & $\mathrm{C} 4$ & A0A2K8HNC7 & $2 \mathrm{CKF}$ & 16.2 & $26 \%$ & 0.74 & $23.68 \%$ \\
\hline & $\mathrm{CP}$ & A0A0S2MSU9 & $6 \mathrm{~F} 2 \mathrm{~S}$ & 394 & $83 \%$ & 1e-140 & $82.79 \%$ \\
\hline & $\mathrm{V} 2$ & A0A0S2MSV4 & $3 \mathrm{FCX}$ & 27.7 & $31 \%$ & 4.0 & $35.14 \%$ \\
\hline CLCuMB & $\beta C 1$ & A0A0K2SU38 & 6JWP & 28.5 & $69 \%$ & 2.6 & $28.05 \%$ \\
\hline \multirow{6}{*}{$\begin{array}{c}\text { ToLCNDV } \\
\text { DNA-A }\end{array}$} & Rep & A0A565D4R1 & $1 \mathrm{~L} 2 \mathrm{M}$ & 208 & $32 \%$ & $3 e-67$ & $82.76 \%$ \\
\hline & TrAP & A7WPF3 & $6 \mathrm{~F} 12$ & 30 & $39 \%$ & 1.1 & $30.36 \%$ \\
\hline & REn & A6PYE1 & $4 \mathrm{NOH}$ & 27.7 & $30 \%$ & 6.4 & $35.56 \%$ \\
\hline & $\mathrm{C} 4$ & A7U6D0 & $3 \mathrm{H} 74$ & 30.8 & $55 \%$ & 0.05 & $37.5 \%$ \\
\hline & $\mathrm{CP}$ & A0A2Z2GPB3 & $6 \mathrm{~F} 2 \mathrm{~S}$ & 367 & $83 \%$ & $7 e-130$ & $78.6 \%$ \\
\hline & $\mathrm{V} 2$ & A0A3G2KQ59 & 1Q9J & 27.7 & $46 \%$ & 3.6 & $40.74 \%$ \\
\hline \multirow{2}{*}{$\begin{array}{c}\text { ToLCNDV } \\
\text { DNA-B }\end{array}$} & NSP & A0A2P2CKV4 & $5 \mathrm{E} 68$ & 30.4 & $8 \%$ & 1.8 & $52.17 \%$ \\
\hline & MP & E6N191 & $3 \mathrm{~N} 2 \mathrm{O}$ & 32.3 & $23 \%$ & 0.81 & $27.27 \%$ \\
\hline
\end{tabular}

5 


\section{Table 2 (on next page)}

Strongest interactions observed in case of inter-viral and Intra-viral infections 
1

2

3

4

\begin{tabular}{|c|c|c|c|c|c|c|c|c|c|}
\hline $\begin{array}{c}\text { Virus/Satellite } \\
1\end{array}$ & Protein & $\begin{array}{c}\text { Virus/Satellite } \\
2\end{array}$ & Protein & $\begin{array}{l}\text { HDK }{ }^{1} \\
\text { Score } \\
\text { a.u. }\end{array}$ & $\begin{array}{l}\text { RMSD } \\
\AA\end{array}$ & $\mathrm{DE}^{2}$ & $\begin{array}{l}\text { VDW }^{3} \\
\text { Energy }\end{array}$ & ESE $^{4}$ & BSA $^{5}$ \\
\hline CLCuKoV-Bu & Rep & CLCuKoV-Bu & Rep & -198 & 25.2 & -131 & -107 & -230 & 2892 \\
\hline CLCuKoV-Bu & Rep & CLCuKoV-Bu & $\mathrm{CP}$ & -193.7 & 21 & -112 & -85 & -184 & 2481 \\
\hline CLCuKoV-Bu & Rep & CLCuKoV-Bu & V2 & -153.6 & 9.9 & -74.7 & -88.6 & -294 & 2459 \\
\hline CLCuKoV-Bu & Rep & ToLCNDV & Rep & -201 & 14.6 & -159 & -138.9 & -450 & 3927 \\
\hline CLCuKoV-Bu & Rep & ToLCNDV & TrAP & -195.1 & 1.9 & -129 & -134 & -177 & 3795 \\
\hline CLCuKoV-Bu & Rep & ToLCNDV & $\mathrm{C} 4$ & -196 & 1 & -104 & -93 & -232 & 2407 \\
\hline CLCuKoV-Bu & Rep & ToLCNDV & $\mathrm{CP}$ & -192.4 & 8.9 & -158 & -100 & -169 & 2903 \\
\hline CLCuKoV-Bu & Rep & ToLCNDV & MP & -279.8 & 10.6 & -125 & -120 & -429 & 3938 \\
\hline CLCuKoV-Bu & Rep & ToLCNDV & NSP & -241.5 & 13.1 & -144 & -130.1 & -197 & 3733 \\
\hline CLCuKoV-Bu & TrAP & ToLCNDV & TrAP & -103 & 2.5 & -41.9 & -105.2 & -220 & 2990 \\
\hline CLCuKoV-Bu & TrAP & ToLCNDV & MP & -134.9 & 0.7 & -23.5 & -86.8 & -256 & 2647 \\
\hline CLCuKoV-Bu & TrAP & ToLCNDV & NSP & -129.6 & 0.7 & -44 & -85.3 & -314 & 2235 \\
\hline CLCuKoV-Bu & REn & ToLCNDV & NSP & -217.8 & 2.1 & -124 & -114 & -333 & 3677 \\
\hline CLCuKoV-Bu & $\mathrm{C} 4$ & ToLCNDV & MP & -160.9 & 1 & -50 & -120.1 & -385 & 3762 \\
\hline CLCuKoV-Bu & $\mathrm{CP}$ & ToLCNDV & TrAP & -185.3 & 0.7 & -95.4 & -131.5 & -345 & 4146 \\
\hline CLCuKoV-Bu & $\mathrm{CP}$ & ToLCNDV & $\mathrm{CP}$ & -163.4 & 0.6 & -112 & -127 & -164 & 3991 \\
\hline CLCuKoV-Bu & $\mathrm{CP}$ & ToLCNDV & MP & -166.9 & 2.1 & -51.5 & 106.1 & -455 & 3553 \\
\hline CLCuKoV-Bu & V2 & ToLCNDV & MP & -199.4 & 0.9 & -63.5 & -106 & -404 & 3092 \\
\hline CLCuMuB & ßC1 & ToLCNDV & $\mathrm{MP}$ & -199.7 & 0.8 & -60 & -115.1 & -500 & 3447 \\
\hline ToLCNDV & TrAP & ToLCNDV & Rep & -191.8 & 0.8 & -137 & -149 & -341 & 4396 \\
\hline ToLCNDV & TrAP & ToLCNDV & TrAP & -120 & 2.5 & -51.9 & -110.2 & -320 & 3990 \\
\hline ToLCNDV & $\mathrm{AC4}$ & ToLCNDV & AC4 & -160.6 & 1 & -80 & -100 & -268 & 2225 \\
\hline ToLCNDV & TrAP & ToLCNDV & $\mathrm{CP}$ & -149.3 & 8.8 & -51.4 & -121 & -430 & 4078 \\
\hline
\end{tabular}

5

$6 \quad{ }^{1}$ HADDOCK; ${ }^{2}$ Desolvation Energy; ${ }^{3}$ Van Der Waals Energy; ${ }^{4}$ Electrostatic Energy; ${ }^{5}$ Buried surface

7 Area; ${ }^{6}$ Restraint Violation Energy
Table 2

Strongest interactions observed in case of inter-viral and Intra-viral infections. 